\title{
Natural-Color Fancy White and FANCY BLACK DIAMONDS: Where Color and Clarity Converge
}

Sally Eaton-Magaña, Troy Ardon, Christopher M. Breeding, and James E. Shigley

Natural Fancy white and Fancy black diamonds are not routinely submitted to GIA for grading (fewer than 2,000 since 2008). These fancy-color diamonds are distinctive since the causes of color generally are not atomic-scale defects, but nanometer- to micrometer-sized inclusions that reduce the diamond's transparency by scattering or absorbing light (some exceptions exist among Fancy black diamonds). To clarify, Fancy white diamonds are those rare stones colored by inclusions that give a "whitish" appearance, and are distinct from "colorless" diamonds on the D-to-Z scale.

These two colors, often thought of as opposites in the color world, are grouped here as outliers within the colored diamond world. Both can be colored by inclusions so numerous the stone would fall below the $I_{3}$ grade on the clarity scale, demonstrating that inclusions, often perceived as a negative quality factor, can create a distinctive appearance. Among the Fancy white diamonds examined for this study, the vast majority (82\%) were type laB, making them a rare subset of a rare diamond type. Based on prior geological research, these are surmised to be mostly sublithospheric in origin (i.e., forming more than $250 \mathrm{~km}$ below the earth's surface). The Fancy white diamonds generally have a different chemistry from D-to-Z type laB diamonds, with greater quantities of several hydrogen- and nickel-related defects. Among Fancy black diamonds, the major causes of color are either micrometer-sized dark crystal inclusions, nanometer-sized inclusions clustered into clouds, or a combination of the two. For these two colors of diamond, we summarize their gemological properties along with the absorption and luminescence spectra of a representative subset of diamonds from each color, examining how they deviate from the standard grading methodology. Because of their rarity, there has been very little systematic study of either of these color categories, and never a sample set of this quantity, which includes data for $\sim 500$ Fancy white and 1,200 Fancy black diamonds.

$\mathrm{W}$ hen discussing the cause of color in diamond, we typically discuss atomic-level defects rather than inclusions-relying more on our spectrometers than our microscopes. Seldom are the diamonds distinguished not by color saturation, but by tone (neutral lightness and darkness) and transparency. Nevertheless, Fancy white and Fancy black diamonds break these rules and exist within their own special category, distinct from the other fancy-color diamonds described previously in our

See end of article for About the Authors and Acknowledgments.

Gems \& Gemology, Vol. 55, No. 3, pp. 320-337,

http://dx.doi.org/10.5741/GEMS.55.3.320

(C) 2019 Gemological Institute of America article series (Breeding et al., 2018; Eaton-Magaña et al., 2018a, 2018b).

Fancy white diamonds, due to their scarcity as faceted stones, comparatively small size, and the lack of notable historical examples, are not well known. They are largely procured by connoisseurs. Probably the most famous of Fancy black diamonds is the Black Orlov (figure 1), a 67.50 ct cushion with a provenance dating back two centuries and, like the Hope diamond, rumored to be "cursed" (Balfour, 2009).

Other famous Fancy black diamonds include the 312.24 ct Mogul-cut Spirit of de Grisogono, one of the world's largest black diamonds, which originated from the Central African Republic. The Gruosi diamond is a $115.34 \mathrm{ct}$ heart shape reportedly discovered in India, and the Korloff Noir is an 88 ct round brilliant. 


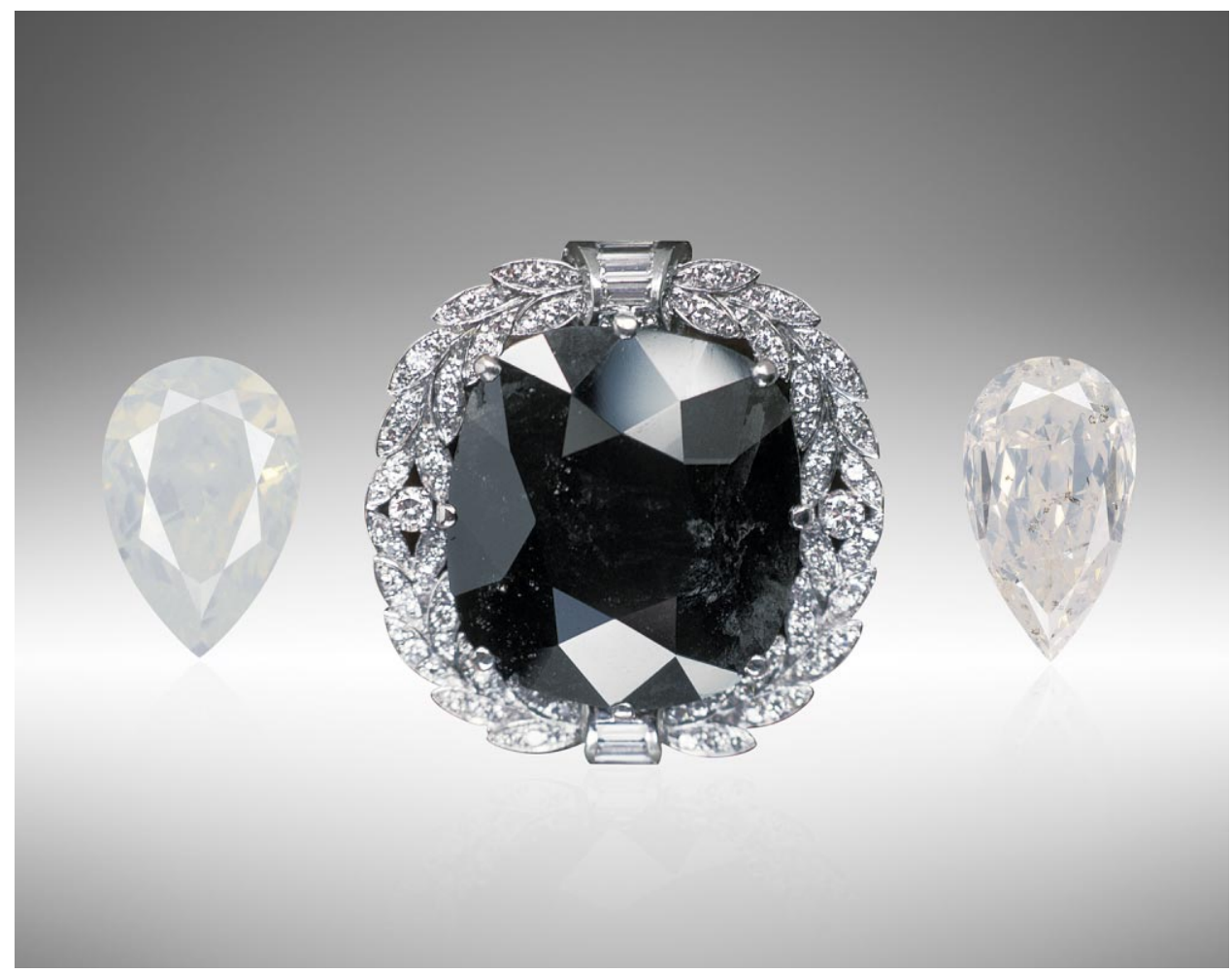

Figure 1. The famous Black Orlov, a $67.50 \mathrm{ct}$ Fancy black diamond, is flanked by two Fancy white diamonds $(2.26 \mathrm{ct}$ and $30.87 \mathrm{ct}$ ). Photos are not to scale. The Fancy white diamond photos are by GIA staff (left) and Jessica Arditi (right).

The appearance of Fancy black and Fancy white diamonds varies more because of differences in trans-

parency than because of variations in saturations or modifying hues (figure 2). They can range from

Figure 2. These examples of Fancy white and Fancy black diamonds do not show major variations in hue or color saturation, but they do vary by transparency. Photos by GIA staff.

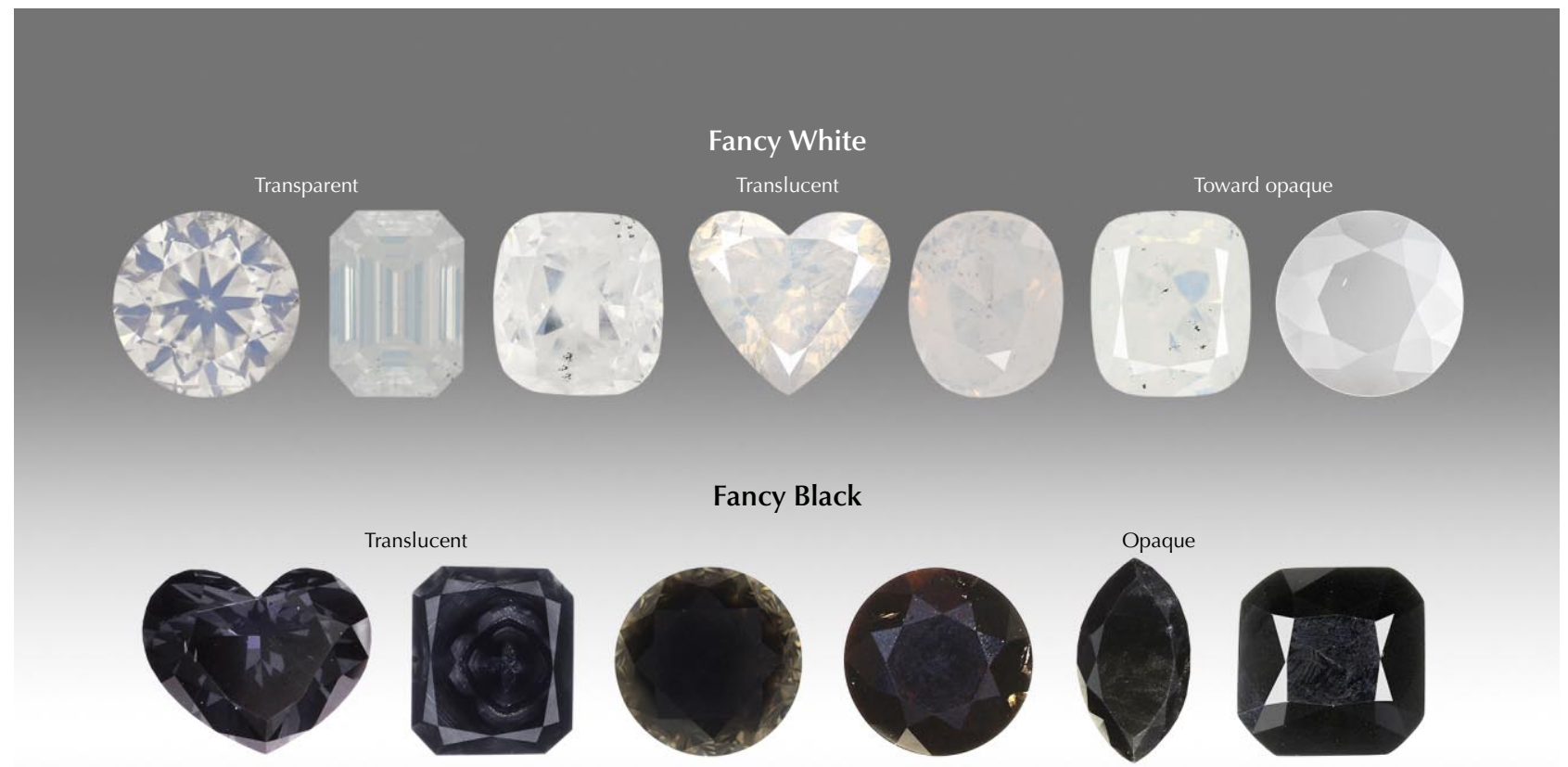




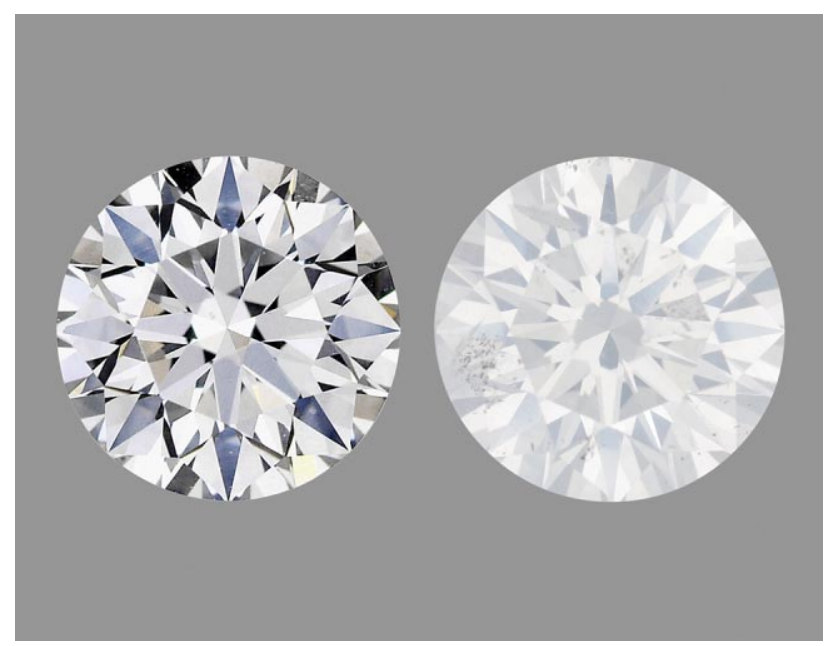

Figure 3. A colorless D-color diamond (left) is often described as "white" in the trade and by consumers. However, such terminology should not be confused with Fancy white diamonds. The E-color diamond with $I_{2}$ clarity and whitish internal graining on the right is one of the color master stones in GIA's Carlsbad lab. It represents the boundary between the D-to$Z$ color scale and those deemed Fancy white. Photos by Robison McMurtry.

transparent to translucent to opaque, but they generally are not transparent. Other natural forms of carbon such as bort, ballas, and carbonado are not submitted to GIA in large quantities and will only be discussed briefly. Additionally, Fancy white diamonds should not be confused with colorless diamonds (those generally graded as D to F), which are often termed "white" within the trade and by consumers (figure 3).

\section{CAUSES OF COLOR}

Fancy White. Fancy white diamonds are sometimes referred to as having an "opalescent" appearance due to the unusual way that light is scattered inside the stone. Gemologists, however, often describe them as "hazy," "milky," or "cloudy" when observing them through a microscope (figure 4). Recent studies on both hazy and cloudy diamonds show that these observations (e.g., Rudloff-Grund et al., 2016; Kagi et al., 2016; Gu et al., 2019) are due to two distinct phenomena: nano-inclusions and dislocation loops, both described below. These studies have shed light on the nature of these features, which can appear nondescript even at high magnifications with an optical microscope. These features are best imaged and identified using more advanced forms of microscopy such as transmission electron microscopy (Rudloff-Grund et al., 2016; Gu et al., 2019). In TEM, a beam of elec- trons is transmitted through the sample to form an image. This tool is capable of much higher resolution than an optical microscope. It is also a destructive test method that requires "foils" made of extremely thin films, generally less than $100 \mathrm{~nm}$, of the diamond (more information on this technique may be found in Titkov et al., 2003).

Rudloff-Grund et al. (2016) showed by TEM the presence of both nano-inclusions and dislocation loops in these milky white diamonds. The nano-inclusions were observed in two distinct size rangesthe majority were 20-30 nm, and some were 150-200 $\mathrm{nm}$. In comparison, inclusions that are large enough to be classified as crystals are generally larger than $\sim 50 \mu \mathrm{m}$ (500 times larger). The nano-inclusions appeared as octahedrons or elongated trapezoids, and were found to contain nitrogen; other researchers have confirmed the presence of nitrogen, but there is

\section{In Brief}

- Fancy white diamonds are predominantly type laB, and their "milky" color originates from nano-inclusions and structural imperfections.

- Fancy black diamonds have a variety of causes of color but are due largely to inclusions (either appearing as clouds of dark nano-inclusions, micron-sized crystal inclusions, or a combination of both).

- As cause of color is generally due to inclusions, these diamonds pose distinct grading challenges.

still no consensus on the exact configuration of the nitrogen (Kagi et al., 2016; Rudloff-Grund et al., 2016; Navon et al., 2017; Gu et al., 2019). Rudloff-Grund et al. also found that areas of the diamond with these nano-inclusions correlated with detection of higher nitrogen and hydrogen by IR absorption mapping. Other researchers (Kagi et al., 2016) additionally found several transition metals (such as Ni) within these nano-inclusions.

$\mathrm{Gu}$ et al. (2019) continued this study by creating TEM foils with diamond that they deemed as only "hazy" or only "cloudy" based on their microscopic differences. They wished to see if distinguishing phenomena could be observed between the "hazy" and "cloudy" descriptions. They found that "hazy" diamonds did not show distinct pinpoints by optical microscopy even when viewed at high magnifications. In contrast, diamonds termed "cloudy" did display distinct pinpoints at high magnifications. 

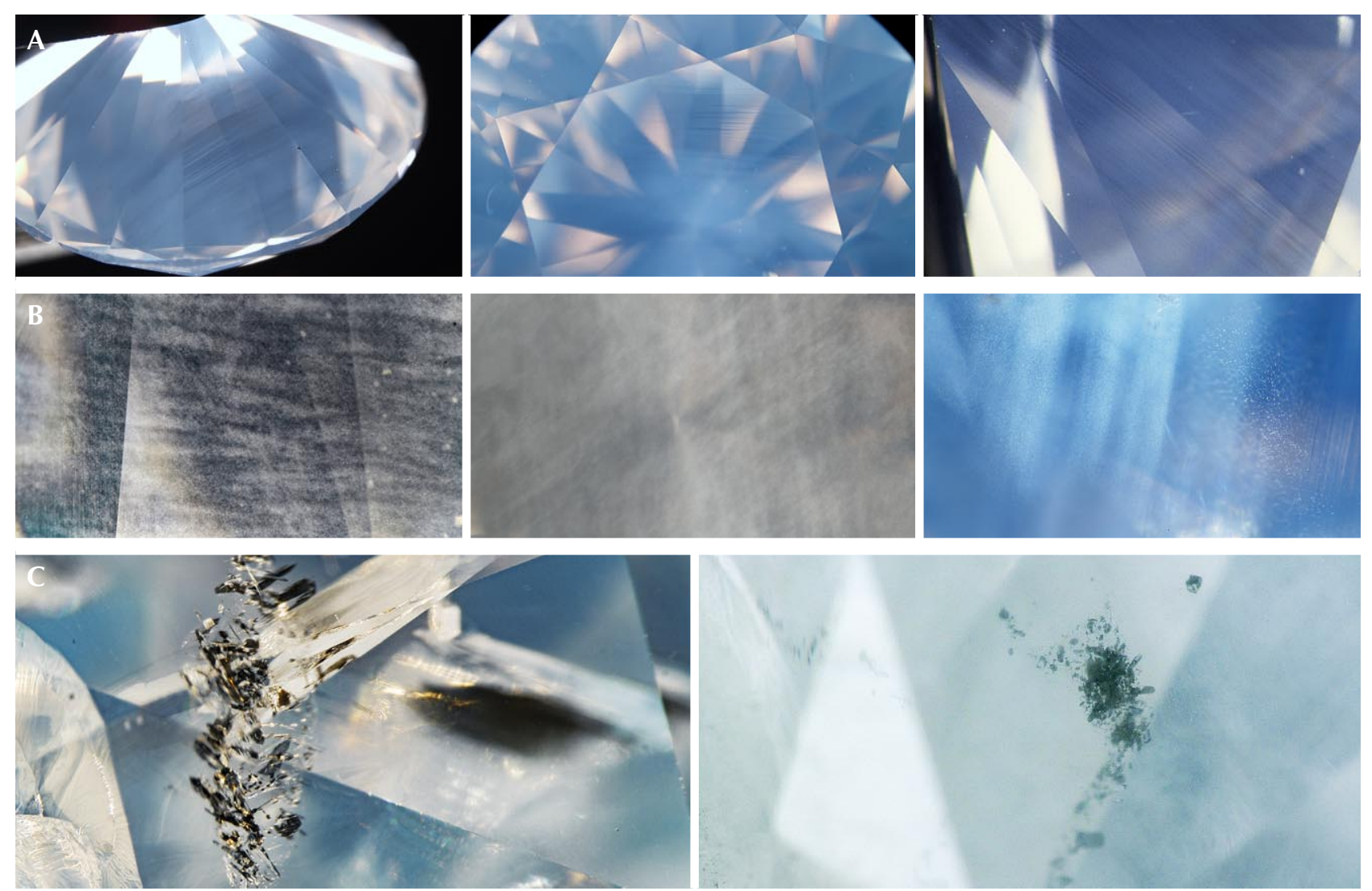

Figure 4. This photomicrograph array shows the variety of observations possible in Fancy white diamonds. The responsible defects can be seen as linear bands (A), crisscrossing bands, or isolated pinpoints (B), and these can be described as "hazy" or "cloudy." Due to the nature of these nano-inclusions, the features can be difficult to photograph. Often present in Fancy white diamonds (e.g., figures 1 and 2) are dark, obvious inclusions (C), generally due to graphitized inclusions or graphitized stress fractures (Jang-Green, 2006). Fields of view: A1: 8.9 mm; A2: 8.0 mm; A3: 2.9 mm; B1: 2.9 mm; B2: 3.6 mm; B3: 1.9 mm; C1: 2.3 mm; C2: 2.5 mm.

TEM showed more differences. In "hazy" diamonds, the TEM results indicated only the presence of dislocation loops. Dislocation loops are created from a disarrangement of the atoms that are disruptions in the crystal lattice (Stukowski et al., 2012). These lattice defects form into a dislocation loop of distorted atoms since the loop exists at a more favorable lower-energy state than the isolated lattice defects themselves. This doughnut-shaped feature of disordered atoms exists within the normal crystal structure. Dislocation loops in diamonds have been experimentally shown to form from platelet defects in type IaB diamonds when heated to very high temperatures $\left(2400-2700^{\circ} \mathrm{C}\right.$; Evans et al., 1995). Platelets are extended defects thought to form when A aggregates transition into $\mathrm{B}$ aggregates; they involve carbon interstitials (i.e., clusters of carbon atoms not in normal positions in the lattice) and nitrogen in thin layers (Humble, 1982; Speich et al., 2017). In these diamonds, dislocation loops are impossible to discern directly with an optical microscope, unlike a foreign inclusion with distinct boundaries; however, the effects of these dislocation loops appear to scatter light.

In contrast with the observations of "hazy" diamonds, in the diamonds that appeared "cloudy" instead, Gu et al. (2019) detected nano-inclusions (described as negative crystals) containing solid nitrogen. As with prior researchers, they confirmed the size ranges of these features as $\sim 20$ to $200 \mathrm{~nm}$.

Fancy Black. There are several different causes of color for natural black diamonds: internal inclusions (such as graphite, non-carbon crystal inclusions, and 

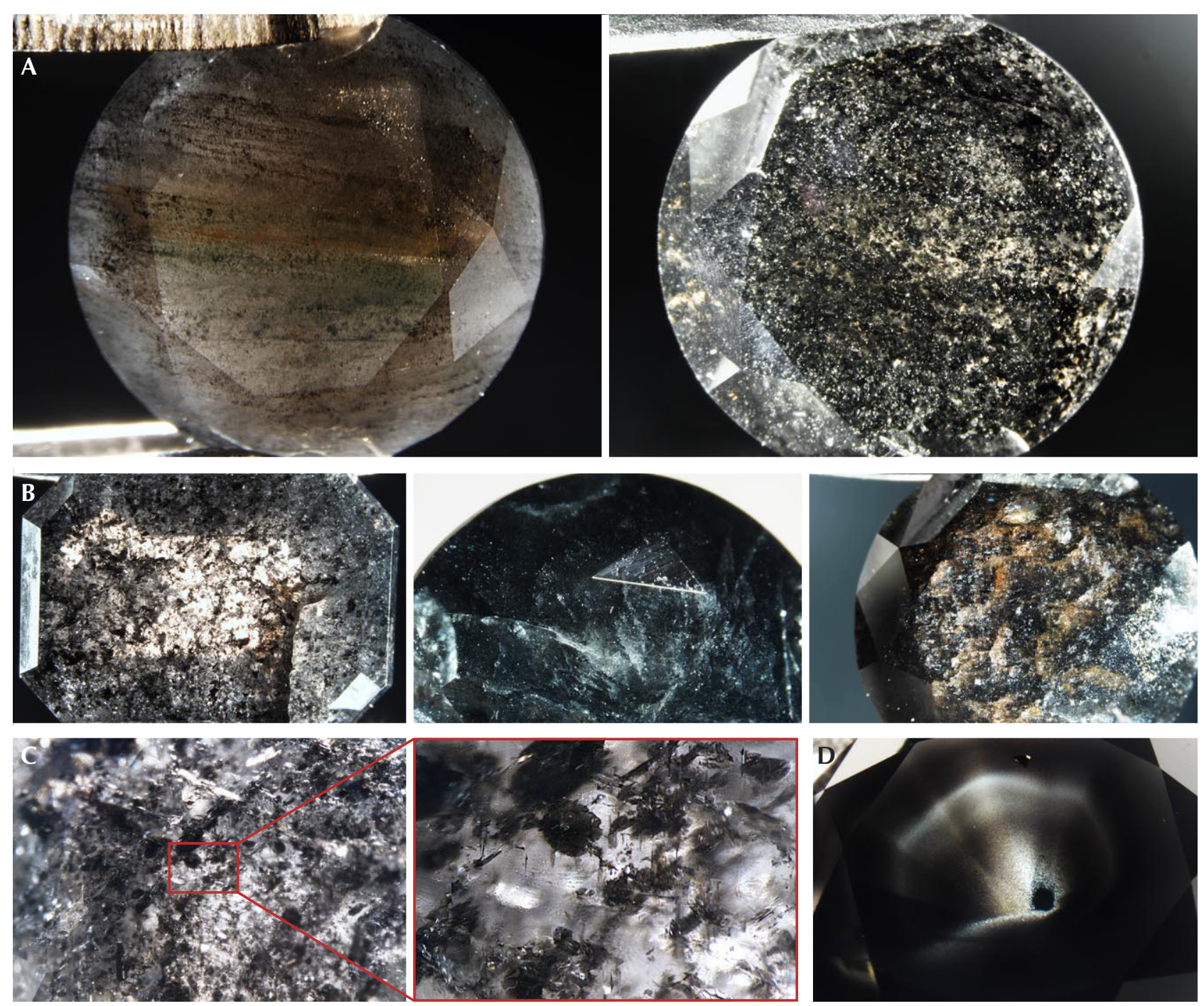

Figure 5. This photomicrograph array shows the variety of observations possible in Fancy black diamonds. Fancy black diamonds are generally very heavily included. Based on the size of the inclusions, they are termed crystals or clouds of pinpoints. All photomicrographs were collected in transmitted light by GIA staff. A: Diamonds can show irregular or linear banding of inclusions. B: Diamonds with masses of dark inclusions; the one on the right also shows iron oxide staining. C: The graphitic inclusions in a Fancy black diamond and a higher-resolution photomicrograph of one area. Image widths of 4.8 and $1.26 \mathrm{~mm}$, respectively. D: Diamond with cloud inclusions. Field of view: A1: $6.7 \mathrm{~mm}$; A2: $9.5 \mathrm{~mm}$; B1: $7.8 \mathrm{~mm}$; B2: $7.5 \mathrm{~mm}$; B3: $8.7 \mathrm{~mm}$; C1: $4.8 \mathrm{~mm}$; C2: $1.3 \mathrm{~mm}$; D: $6.9 \mathrm{~mm}$.

clouds; figure 51, high-density radiation stains along surfaces or fractures (usually contributing to a darker appearance), and in rare cases very high absorption across much of the visible spectrum that results from atomic or extended lattice defects.

Crystals. Kammerling et al. (1990) described a set of black diamond jewelry and used microscopic observation to identify the inclusions as graphite. Titkov et al. (2003) later studied a suite of black diamonds they had sourced from Siberia in Russia (principally from the Mir kimberlite pipe). In their samples from that locality, graphite inclusions were rare and instead the inclusions they found were mostly magnetite $\left(\mathrm{Fe}_{3} \mathrm{O}_{4}\right)$, hematite $\left(\mathrm{Fe}_{2} \mathrm{O}_{3}\right)$, and native iron. These inclusions were determined by individually studying their chemical compositions using energy-dispersive X-ray spectroscopy (EDX). More recently, Smit et al. (2018) 
studied an extensive suite of faceted black diamonds sourced from the Marange alluvial deposits in Zimbabwe, and many of these showed graphite inclusions that generally appeared as needles.

Clouds. Here, clouds are distinguished from the inclusions described above by their size. Clouds are generally described as a cluster of tiny pinpoint inclusions. They can vary in density (and therefore transparency), and some examples show a distinct outline while others are spread through the diamond. At 10x magnification, the morphology of individual pinpoints that make up a "cloud" cannot be distinguished. The Marange black diamond suite (Smit et al., 2018) also showed a few examples (4 of 40) in which dark clouds previously identified as graphite (Smit et al., 2016; Eaton-Magaña et al., 2017) were the source of the Fancy black coloration. These clouds are often associated with high quantities of hydrogen in IR spectra (Johnson, 2008).

Radiation Stains. Radiation stains on diamond surfaces, created from physical contact with a radiation source (typically a radioactive mineral grain or fluid; Breeding et al., 2018) can appear as either green or brown depending on subsequent temperature exposure, as green radiation stains generally become brown at temperatures of $\sim 550^{\circ} \mathrm{C}$ (Nasdala et al., 2013). Although not always found in black diamonds, and generally observed in conjunction with inclusions and clouds described previously, abundant brown radiation stains in highly fractured diamonds are occasionally seen (particularly from Marange). When enough stain-filled fractures are present in a stone, it has a very dark overall appearance. However, shining a bright light from behind the diamond (i.e., transmitted light) reveals the green or brown appearance due to the radiation stains.

Absorption Defects. Although this cause of color is more common among treated diamonds (described below), pronounced absorption across much of the visible spectrum due to high concentration of atomic or extended defects can lead to a Fancy black color. When the stone is viewed through the pavilion, depending on the defect, it can often appear violet (Breeding and Rockwell, 2009; Johnson, 2011) or green, though the face-up color is Fancy black. If the absorbing defect had a lower concentration or the stone had a smaller size, the diamond may have received the corresponding color description instead of Fancy black.
Polycrystalline Diamond. Carbonado is a naturally occurring polycrystalline diamond material composed of randomly oriented cuboidal microcrystals (about 5-20 $\mu \mathrm{m}$ in size; Haggerty, 2017). The cumulative effect of these microcrystals along with the incorporation of non-diamond carbon material is that the carbonado appears opaque and generally black, gray, or brown. Carbonados have occasionally been faceted as gems (De Corte et al., 2004; Wang et al., 2009|, but their polycrystalline structure and variation in polishing directions makes it difficult to achieve a flat, reflective polished facet surface.

\section{OCCURRENCE AND FORMATION}

Fancy White. Fancy white diamonds are predominantly type IaB (i.e., showing only B-form nitrogen aggregates in their IR spectra; see Breeding and Shigley, 2009 for more on diamond types). The B aggregate has been identified as four nitrogen atoms surrounding a vacancy (Boyd et al., 1995), and it is generally considered the end product of the nitrogen aggregation process; geologically young diamonds show nitrogen as single isolated atoms that coalesce over geologic time into pairs (A aggregates). This pairing of nitrogen atoms (and the subsequent steps of aggregation) involves internal diffusion at relatively high temperature and/or long geologic residence times during which the nitrogen atoms can move through the lattice. During the next stage of aggregation, the A centers form B aggregates, and there is a minor side reaction (Woods, 1986) that produces N3 centers (three nitrogen atoms with a vacancy). Generally, if all A aggregates have converted to B aggregates in a diamond to form a type $\mathrm{IaB}$ diamond, we can conclude that it is geologically quite old or was subjected to higher than normal temperatures that encouraged aggregation, or we can assume a combination of both time and temperature. Since the vast majority of Fancy white diamonds are type IaB, this review of nitrogen aggregation is a good starting point to recount what is known about the elusive cause of color in these diamonds.

Several researchers have studied "milky" diamonds and concluded, based on mineral inclusions, that these type IaB diamonds have an origin from the transition zone or the lower mantle $(400-670 \mathrm{~km}$ depth; Rudloff-Grund et al., 2016; Kagi et al., 2016; Gu and Wang, 2017; Gu et al., 2019). Most diamonds shown to have a superdeep origin are type II diamonds (Smith et al., 2016, 2018). Meanwhile, the vast majority of nitrogen-containing diamond (D-to-Z color 
type Ia and yellow type $\mathrm{Ib}$ ) form in the continental lithosphere (depths of $\sim 140-200 \mathrm{~km}$; Shirey and Shigley, 2013). Those studied diamonds ("milky," type IaB) were subjected to unusual conditions for nitrogen-containing diamonds, such as higher pressures and temperatures corresponding to their deeper origin. These conditions could have instigated the complete aggregation of B centers, and the high temperature could promote some of the other unique characteristics that were observed, such as the destruction of platelets and the formation of dislocation loops.

Gu and Wang (2017) tested 50 milky type IaB diamonds with inclusions that could be identified by Raman spectroscopy. A majority of them contained mineral inclusions from the sublithospheric mantle, such as walstromite, Ca-perovskite, and ferropericlase, which they considered fragments of phases in the transition zone or lower mantle $(>400 \mathrm{~km}$; Shirey and Shigley, 2013).

To our knowledge, there are no reliable geographical sources for Fancy white diamonds. However, a few examined by GIA have come from the Panna mine in India (Koivula et al., 1992), and there have been some scientific reports on "milky" sub-lithospheric type IaB diamonds sourced from the Juina mine in Brazil (Rudloff-Grund et al., 2016; Kagi et al., 2016).

Fancy Black. The geographic sources of most Fancy black diamonds are uncertain, and these are likely quite rare at most mines. If colored by mineral inclusions, there are several possible origins. Many black diamonds that contain radiation stains may be sourced from mines known for naturally irradiated material like Marange in Zimbabwe.

Graphite Crystal Inclusions and Clouds. As with Fancy white diamonds, there is evidence that Fancy black diamonds colored by graphite (either as crystals or as clouds) are also influenced by rapid growth. Smit et al. (2018) showed that all of the diamonds in a suite from Marange contained evidence of nickel (926 nm PL peak using $830 \mathrm{~nm}$ excitation) and high amounts of hydrogen (such as a $3107 \mathrm{~cm}^{-1}$ peak in IR spectra), while a good percentage contained evidence of methane $\left(\mathrm{CH}_{4}\right.$, as a $3050 \mathrm{~cm}^{-1}$ peak in IR spectra; Smit et al., 2018 and references therein). This combination of spectral features coincides with those seen in the cuboid sectors of mixed-habit growth-natural diamonds that contain simultaneously grown cuboid and octahedral sectors where each sector has very distinct chemistry and inclu- sions. These cuboid sectors grow faster than octahedral sectors, and this rapid growth allows them to incorporate micron-sized cavities (Klein-BenDavid et al., 2007) along with a greater variety and concentration of impurities and inclusions than the octahedral regions (Lang, 1974). Therefore, these cuboid sectors have higher concentrations of non-diamond carbon (such as graphite and methane) and other impurity elements such as nickel and hydrogen. There is likely some similarity in the formation of these black diamonds, as with the cuboid sectors of mixed-habit diamonds. The Marange alluvial deposits have been a steady source of graphite-bearing diamonds for several years, although it is likely not the only source of graphite-included black diamonds, as some gemological reports (e.g., Kammerling et al., 1990) predate the Marange discovery. Additionally, Marange is unique as a source of diamonds exposed to high levels of radiation (Smit et al., 2018), with many containing abundant brown radiation stains in fractures that contribute to their Fancy black coloration.

Non-Carbon Inclusions. Although several reports have chronicled Fancy black diamonds with color due to non-carbon inclusions (e.g., Win and $\mathrm{Lu}, 2009$ ), to our knowledge the only analyzed samples with a known locality were those reported by Titkov et al. (2003). These contained magnetite $\left(\mathrm{Fe}_{3} \mathrm{O}_{4}\right)$, hematite $\left(\mathrm{Fe}_{2} \mathrm{O}_{3}\right)$, and native iron and were sourced from the Mir kimberlite field in Siberia, which is also a known source for pink to purple diamonds (Titkov et al., 2008).

Carbonado. According to previous reports, carbonado has only been found in Brazil and the Central African Republic (Haggerty, 2017), and its method of formation remains unknown. Several theories regarding how the material originated have been proposed, such as sintering in the earth's crust and a potentially extraterrestrial origin.

\section{LABORATORY GRADING}

Grading of Fancy white and Fancy black diamonds poses unique challenges, as their limited transparency makes some observations difficult. At GIA, these stones' transparency is evaluated to determine if a Colored Diamond Grading (CDG) report may be issued. In an opaque stone, for example, a grader cannot look through the table to the pavilion facets and properly judge symmetry as one would in a transparent stone. Therefore, most Fancy white and almost 


\section{QUALITY FACTORS FOR FANCY WHITE AND FANCY BLACK DIAMONDS}
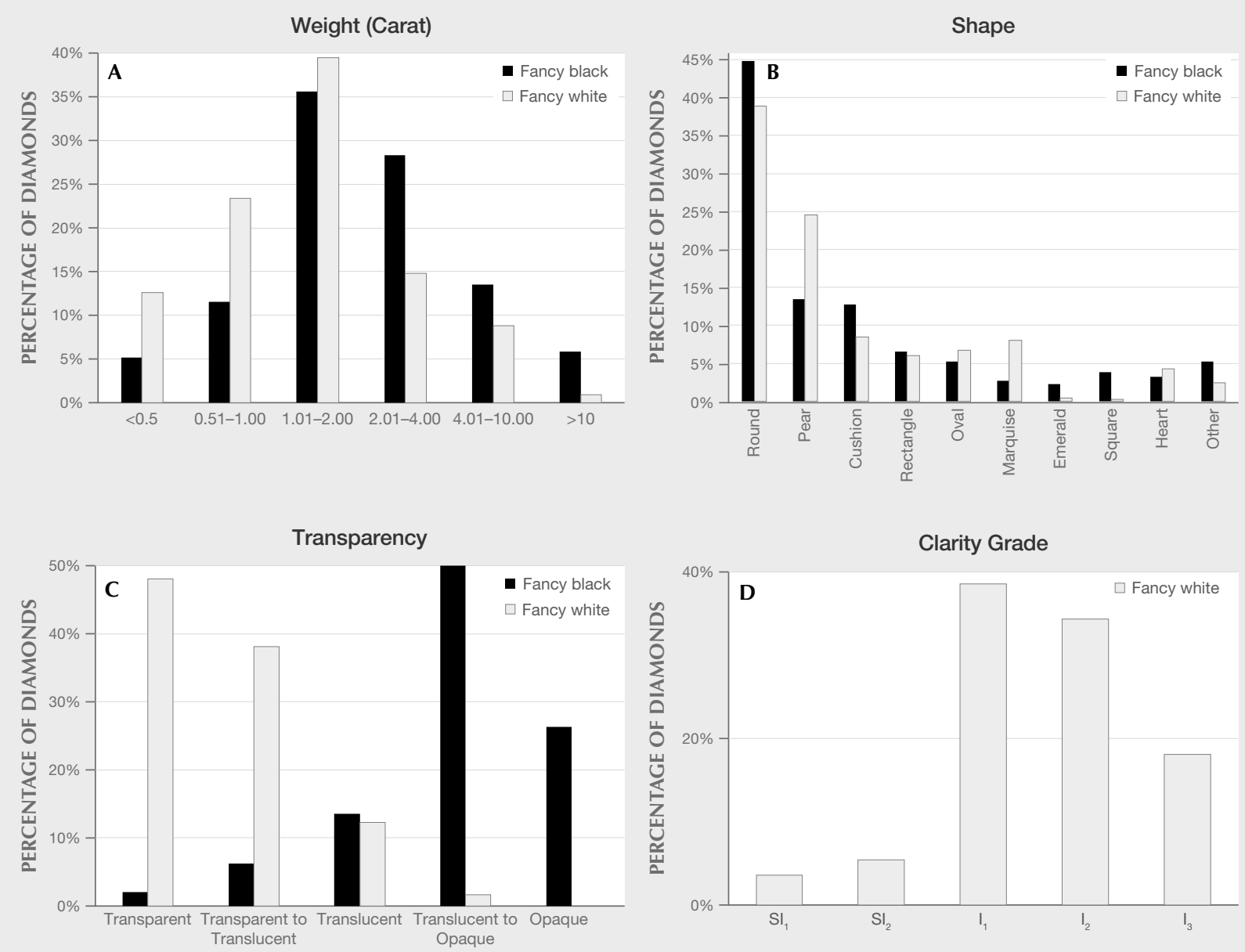

Figure 6. Quality factors for Fancy white and Fancy black diamonds analyzed by GIA, 2008-2016: weight (A), shape (B), transparency $(C)$, and clarity grade $(D)$. Transparency observations and clarity grades were not recorded for all submitted diamonds.

all Fancy black stones submitted have received a Colored Diamond Identification and Origin report. (The CDIOR determines origin of color and certifies if a diamond is natural, treated, or synthetic; it should not be confused with a Diamond Origin report, which states country of origin.) Of the Fancy white diamonds submitted in the last ten years, about $30 \%$ were issued CDG reports and the balance received CDIOR reports. The clarity grades shown in figure 6 are taken from this small subset.

Figure 6 shows the distribution of Fancy white and Fancy black diamonds according to several quality factors and observations. In figure 6A, the weight distribution for Fancy white and Fancy black diamonds indicates that Fancy white diamonds skew to- ward smaller sizes with $\sim 75 \%$ having weights of less than 2 carats. The shape distribution in figure $6 \mathrm{~B}$ reveals that a plurality of both colors have a round shape. Figure 6C provides the transparency distribution-a comparison not often made for other diamonds. This plot shows the distribution among those for which a transparency was recorded based on the judgment of the GIA gemologist. According to the plot, the majority of Fancy white diamonds skew toward a transparent observation. Figure 6D shows the clarity grade distribution among those Fancy white diamonds for which a clarity grade could be assigned, and almost all are in the Included range. The majority of Fancy white and nearly all Fancy black diamonds did not satisfy the criteria for 


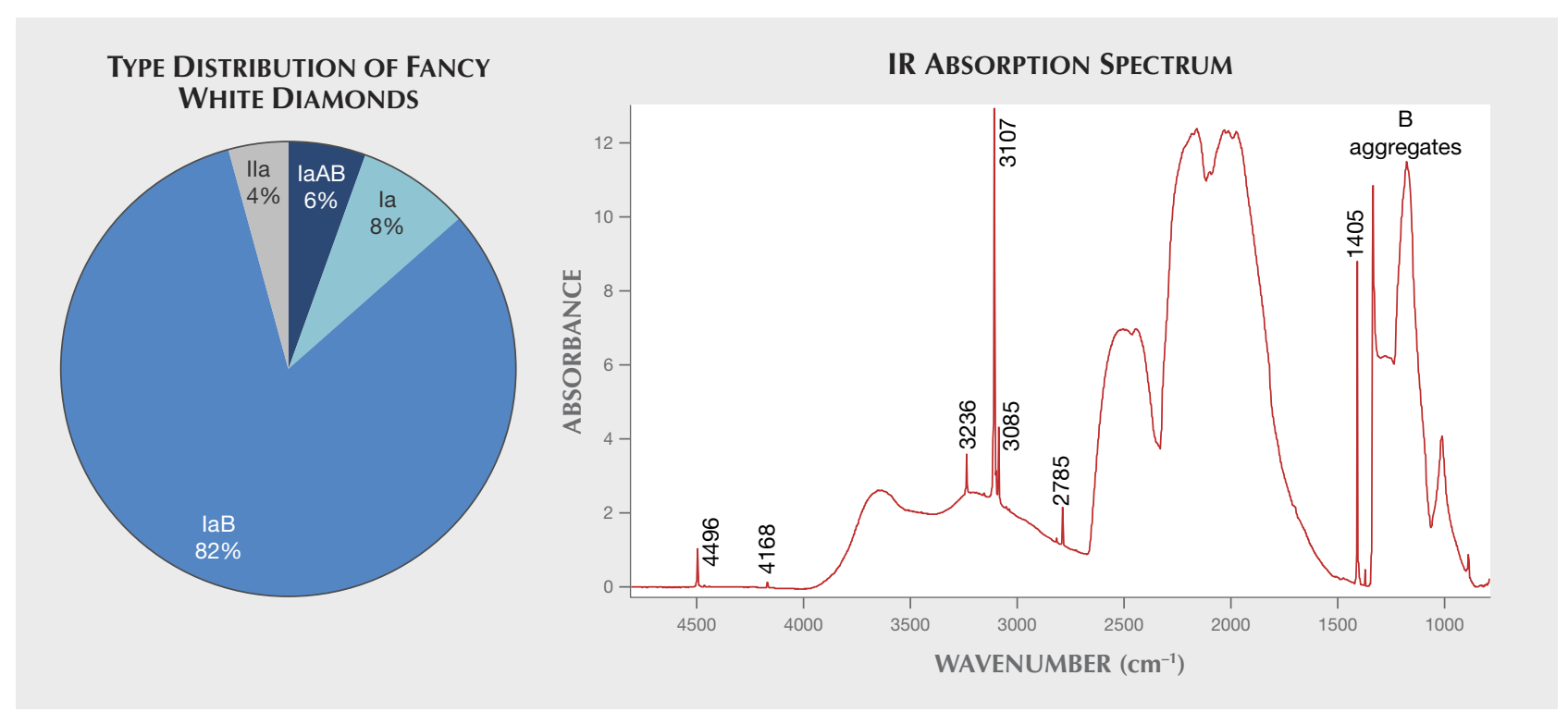

Figure 7. The vast majority of Fancy white diamonds are type IaB. The diamond types were determined for a survey of 400 randomly selected Fancy white diamonds in which $82 \%$ were type IaB (left). Another $8 \%$ were type Ia, meaning the aggregated nitrogen absorption was so strong that it saturated the detector and the A/B aggregate ratio could not be determined. The remaining diamonds were either type IIa or type IaAB. At right, a representative absorption spectrum is shown for a $1.06 \mathrm{ct}$ type IaB Fancy white diamond. Also shown are several hydrogenrelated peaks (Fritsch et al., 2007).

a CDG report (instead of a CDIOR) and are not represented in this plot; if plotted, they would skew toward lower clarity grades.

\section{SPECTROSCOPY}

Standard testing conditions and instrumentation are applied to all diamonds submitted to GIA. These methods have been detailed in other publications (e.g., Smit et al., 2018) and summarized for this series of articles in Breeding et al. (2018).

Fancy White. Infrared Absorption. As mentioned earlier, the vast majority of Fancy white diamonds have been shown to be type IaB. We quantify it here by randomly selecting a subset of 400 Fancy white diamonds and examining their infrared absorption spectra (figure 7) and long-wave fluorescence (discussed below). Of these 400 Fancy white diamonds, $32(8 \%)$ had saturated type Ia infrared spectranamely, there was so much nitrogen in the diamond that we could only determine its presence but not its concentration or $\mathrm{A} / \mathrm{B}$ ratio because the corresponding spectral features exceeded the absorption range of the instrument detector. An additional $22(6 \%)$ were type $\mathrm{IaAB}$ and $17(4 \%)$ were type IIa. The remaining 329 diamonds ( $82 \%$ ) were able to be classified as type IaB. Since the percentage of type $\mathrm{IaB}$ diamonds among all diamonds submitted to GIA is $\sim 0.1-0.2 \%$ (internal GIA statistics), the conditions to produce type IaB diamonds are very rare and those necessary to produce Fancy white diamonds even more so.

Comparison to Other Type IaB Diamonds. To try to discern any additional spectroscopic information that distinguishes Fancy white diamonds, we compared three groups of type IaB diamonds:

1. A randomly selected population of 100 type IaB without a cloudy/hazy/milky appearance, and with high clarity grades (VVS or higher) and good color (majority D-F).

2. A randomly selected population of 100 type IaB diamonds with a cloudy/hazy/milky appearance, as evidenced by low clarity grades (generally SI to I), that must contain clarity characteristics such as clouds and pinpoints, and potentially a "hazy" comment on the worksheet by the grader. However, the diamond was still on the D-to-Z scale (majority D-F).

3. A randomly selected population of 100 type IaB diamonds that were color graded as Fancy white (selected from the 329 type IaB diamonds mentioned above). 


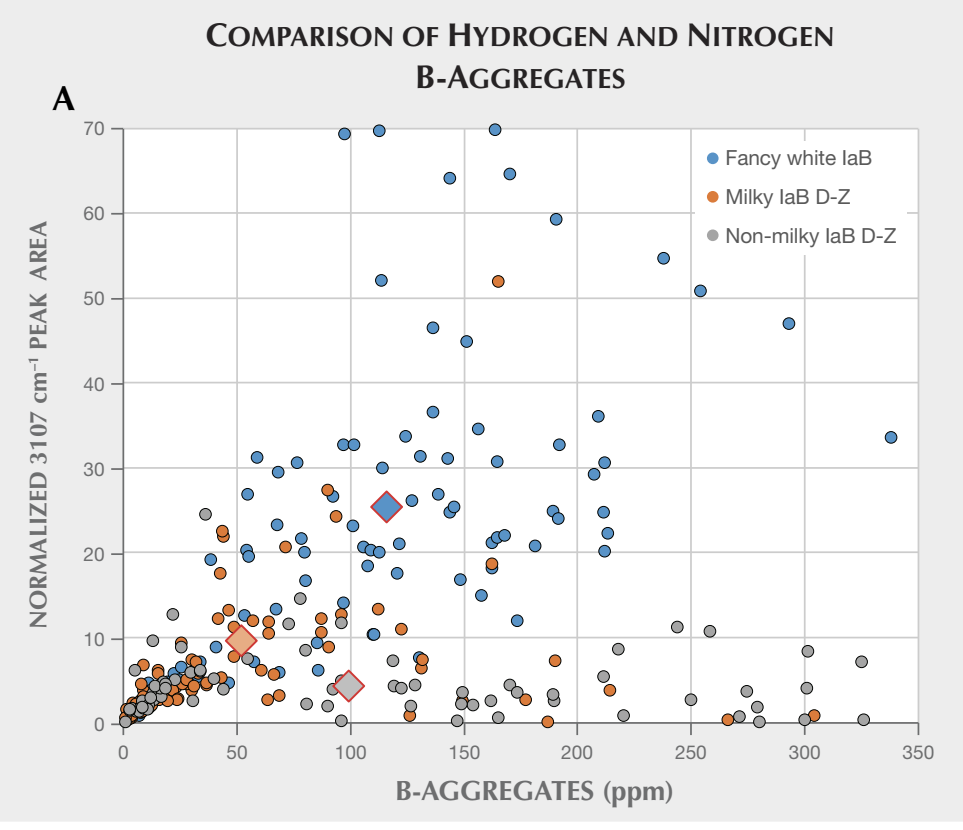

Comparison of Hydrogen-Related PeAKs

B Fancy white laB

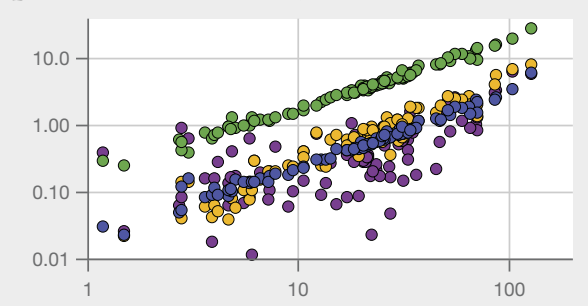

Milky laB D-Z

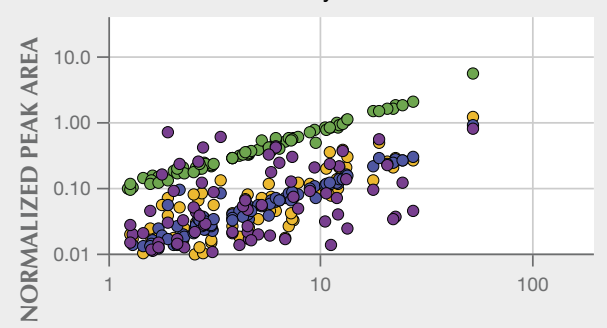

Non-milky laB D-Z

C

\section{NiCKel-Related PL PeAKS}

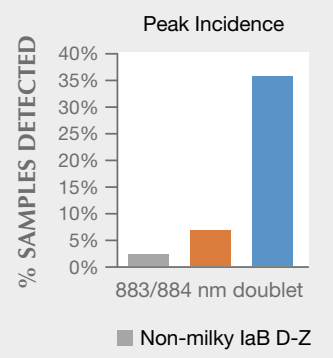

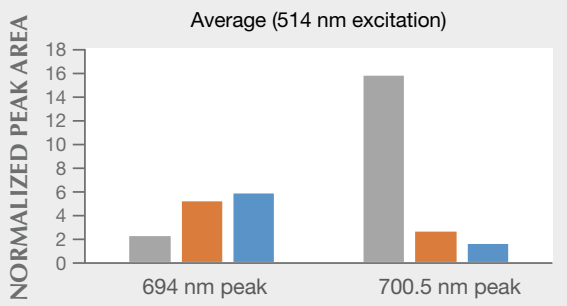

Milky laB D-Z Eancy white laB

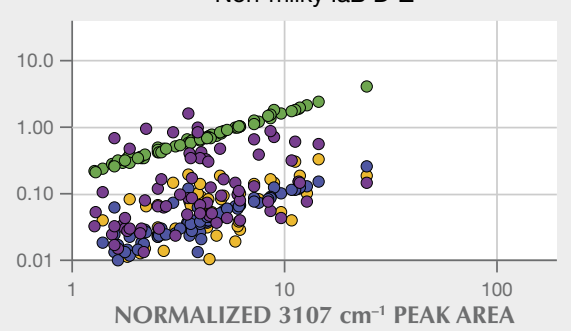

- $3236 \mathrm{~cm}^{-1} \quad 2785 \mathrm{~cm}^{-1}$

○ $3085 \mathrm{~cm}^{-1} \quad 01405 \mathrm{~cm}^{-1}$

Figure 8. To better understand the optical properties that distinguish Fancy white type IaB diamonds from those on the D-to- $Z$ scale, we compared three groupings of type IaB diamonds. Comparing the B aggregate concentration (ppm) and the normalized $3107 \mathrm{~cm}^{-1}$ peak area, the Fancy white diamonds have high concentrations of both nitrogen and hydrogen $(A)$. The diamond-shaped markers in $(A)$ indicate the average values for each grouping. The $3107 \mathrm{~cm}^{-1}$ peak area shows a positive trend with a few other hydrogen-related peaks (B), and the Fancy white diamonds have the highest intensities of hydrogen. Fancy white diamonds also show the highest incidence $(C)$ of the 883/884 nickel doublet and the highest occurrence of the $694 \mathrm{~nm}$ PL peak (identified as a Ni-N complex).

We wished to see if there was any progression in IR absorption and PL spectroscopic features among these three groups. Gu and Wang (2018) had previously looked at the optical features in "milky" type IaB diamonds but grouped categories 2 and 3 together. The most interesting results from comparing these three categories are presented in figure 8 .

Figure $8 \mathrm{~A}$ shows the distribution of $\mathrm{B}$ aggregates (or total nitrogen, as these are type IaB diamonds) versus the $3107 \mathrm{~cm}^{-1}$ normalized peak area. ${ }^{1}$ The 3107 $\mathrm{cm}^{-1}$ peak has been identified as the $\mathrm{N}_{3} \mathrm{VH}$ center; this may be visualized as an N3 center (ZPL at $415.2 \mathrm{~nm}$; often responsible for blue fluorescence in diamond) with a hydrogen atom located within the vacancy (Goss et al., 2014). For the 100 diamonds in each of the

\footnotetext{
${ }^{1}$ It is generally accepted that the absorption coefficient of diamond is constant in the two- and three-phonon regions. For example, at 2000 $\mathrm{cm}^{-1}$ the absorption coefficient is $12.3 \mathrm{~cm}^{-1}$ (Tang et al., 2005; Breeding and Shigley, 2009) and each diamond IR spectrum, regardless of the thickness or path length, can be compared by applying this normalization. Because the two-phonon region was often saturated in these spectra, however, we normalized each IR spectrum using the third-phonon region. The area of each hydrogen-related peak (the area above the baseline) was then determined from the normalized spectra.
} 
three groups described above, the data for nitrogen and hydrogen were determined from each sample's IR spectrum and the averages were calculated and plotted. Figure 8A shows that Fancy white diamonds have both high amounts of hydrogen (as the $3107 \mathrm{~cm}^{-1}$ peak) and high $B$ aggregates. The non-milky, high-clarity D-to-Z diamonds also contain high amounts of B aggregates but comparatively low concentrations of hydrogen. In between these two groups are the milky D-to-Z diamonds that show lower nitrogen than both the non-milky and Fancy white diamonds; however, they contain higher amounts of hydrogen than the non-milky D-to-Z diamonds. From these results, it appears that hydrogen-related defects contribute to the milky appearance. It also appears that higher amounts of nitrogen and hydrogen help distinguish between a milky D-to-Z diamond and one with a Fancy white color grade. Finally, figure 8A shows that for all three groups, when B aggregates (lower left corner of graph) are low in concentration, there appears to be a trend between the nitrogen concentration and $3107 \mathrm{~cm}^{-1}$ peak area; however, the data begin to scatter for nitrogen concentrations greater than $30 \mathrm{ppm}$.

The corresponding intensity between nitrogen concentration and the $3107 \mathrm{~cm}^{-1}$ peak in the Fancy white diamonds seems to indicate that nitrogen concentration is the limiting factor, and that hydrogen is available in excess and probably exists in the diamond in other configurations that may not be IR active (i.e., producing no spectral features due to hydrogen in the infrared spectrum). In contrast, the non-milky, high-clarity type IaB diamonds have comparatively low $3107 \mathrm{~cm}^{-1}$ intensities even with high nitrogen concentrations; this likely indicates that hydrogen is the limiting factor for those diamonds in forming the $3107 \mathrm{~cm}^{-1}$ center.

Figure $8 \mathrm{~B}$ shows the linear relationship between the most prominent hydrogen-related peak at 3107 $\mathrm{cm}^{-1}$ (again, see figure 7B) and other IR peaks associated with hydrogen. Several peaks are part of the 3107 $\mathrm{cm}^{-1}$ system (e.g., 1405, 2785, 4168, and $4496 \mathrm{~cm}^{-1}$; Fritsch et al., 2007). This linear relationship holds between all three groups, though, as mentioned above, the Fancy white diamonds have the highest hydrogen concentration. Also shown are the intensities of the 3085 and $3236 \mathrm{~cm}^{-1}$ peaks that are also ascribed to hydrogen-related peaks, but not part of the $3107 \mathrm{~cm}^{-1}$ system (Fritsch et al., 2007). Although these peaks show more scatter in figure $8 \mathrm{~B}$, they do maintain a positive trend, with increasing $3107 \mathrm{~cm}^{-1}$ peak intensity. Therefore, if these other hydrogen-related peaks are more often seen in Fancy white diamonds than in other type IaB diamonds (e.g., Gu and Wang, 2018), it is likely ascribed to a higher overall amount of hydrogen in those diamonds.

Additionally, detection of the platelet peak was seen to decrease within the milky diamonds. In the non-milky D-to-Z type IaB diamonds, 22 of the 100 showed a platelet peak, generally positioned at $\sim 1360$ $\mathrm{cm}^{-1}$. Among the milky D-to-Z IaB diamonds, only four displayed a platelet peak, all positioned at $~ 1360$ $\mathrm{cm}^{-1}$. Among the Fancy white IaB diamonds, none had a platelet peak. The lack of platelet peaks in these Fancy white diamonds is consistent with the prior observation that dislocation loops-features seen in milky and Fancy white diamonds-can form from the destruction of platelets at high temperatures. This observation is also consistent with the supposition that these have a superdeep origin.

Figure 8C shows the trends seen for some nickelrelated peaks when measured by PL spectroscopy. The milky D-to-Z and especially the Fancy white IaB diamonds show a pronounced difference in peak intensity (or incidence) of nickel-related peaks. The $883 / 884 \mathrm{~nm}$ doublet is quite rare in the non-milky type IaB diamonds (found in only $2 \%$ ), whereas it is detected in more than one-third of Fancy white diamonds. This nickel-related doublet is commonly detected in HPHT synthetics and some low-nitrogen natural diamonds (Collins et al., 1998), and is ascribed to an interstitial $\mathrm{Ni}^{+}$ion along the $<111>$ direction. The 694 and $700.5 \mathrm{~nm}$ PL peaks are both ascribed to $\mathrm{NiN}_{\mathrm{x}}$ complexes. For the non-milky Dto-Z diamonds, we see the $700.5 \mathrm{~nm}$ PL peak as dominant, whereas for the Fancy whites the $694 \mathrm{~nm}$ PL peak is greater. Although the exact compositions of these two nickel-related peaks are unknown, the $700.5 \mathrm{~nm}$ PL peak is dominant in other natural diamonds such as chameleons (Hainschwang et al., 2005). In the highly included, high-hydrogen cuboid sectors of mixed-habit diamonds, however, the 694 $\mathrm{nm}$ peak is dominant (Eaton-Magaña et al., 2017), as with the Fancy white diamonds documented here. As shown in figure 9, the peak area intensity of the $694 \mathrm{~nm}$ peak is significantly greater within the cloudy portion of a Fancy white diamond.

Fancy Black. For the vast majority of Fancy black diamonds, Vis-NIR absorption spectra are not helpful for determining the cause of color. Their color is due to inclusions and not lattice defects, and microscopy is far more diagnostic for inclusions than spectroscopy. Among a randomly selected subset of 1,000 Fancy black diamonds, 536 had IR absorption spectra 

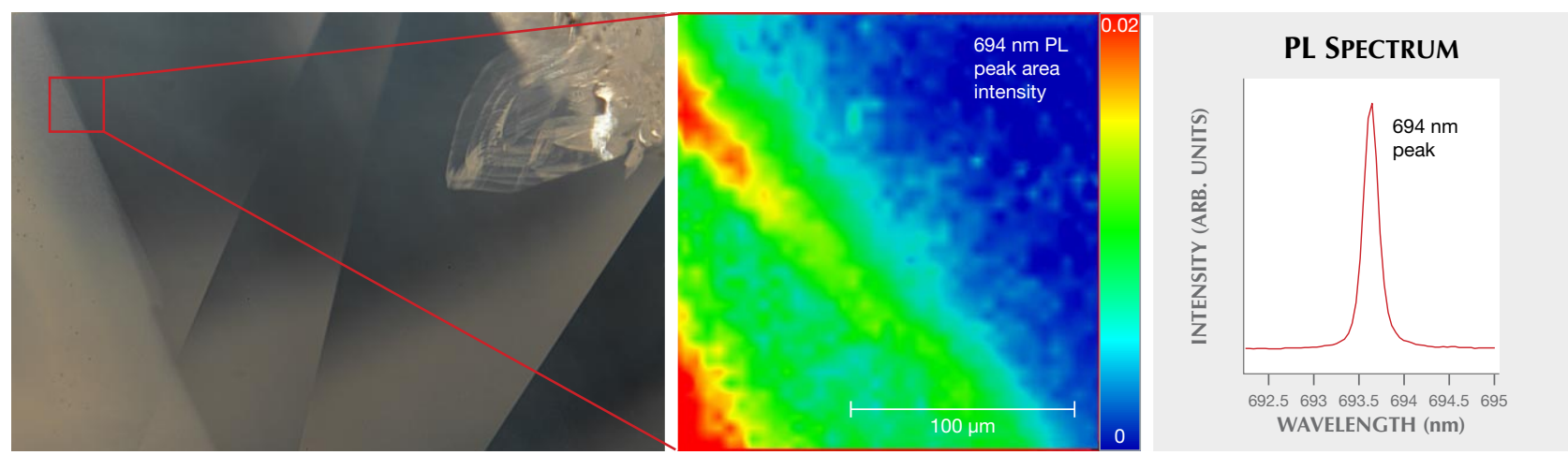

Figure 9. A 3.04 ct Fancy white diamond (left) was used to produce a PL map (center) using 532 nm excitation at the boundary between the clouded area and unclouded area; the false-color map corresponds to the intensity of the $694 \mathrm{~nm}$ peak (peak area normalized using the diamond Raman area). The whitish cloud in the left portion of the image (indicated by the red square in the photomicrograph) and in the PL map corresponds with a much higher intensity of the $694 \mathrm{~nm}$ peak (right) _ a nickel-related peak often seen in Fancy white diamonds and, as shown here, within the clouds themselves. Photomicrograph by Garrett McElhenny; field of view $2.34 \mathrm{~mm}$.

available for examination. Due to the opacity of most Fancy black diamonds, meaningful spectra could not be collected on many of them. Of those 536 with useful spectra available, most $(436$, or $81 \%)$ were saturated type Ia with high nitrogen concentrations, and many also showed very high intensities of hydrogenrelated peaks (figure 10). Diamonds with high hydrogen concentrations would be expected in diamonds containing cloud inclusions. Additionally, many of the diamonds with graphite inclusions had high quantities of hydrogen detected in them as well.

As with Fancy white diamonds, Fancy black diamonds show a positive trend between various hydro- gen-related peaks, although there is significantly more scatter. In contrast with the Fancy white diamonds (figure 8B), the $3085 \mathrm{~cm}^{-1}$ peak has very low intensity in Fancy black diamonds (if detected) and is not shown in figure 10. Also, it was mentioned in the previous section that Fancy white diamonds had high quantities of hydrogen; when compared to the non-milky D-to- $Z$ diamonds, the intensities of the $3107 \mathrm{~cm}^{-1}$ peak are up to one order of magnitude greater. The hydrogen concentrations (as shown in the IR absorption spectrum in figure 10) are even greater still, with values another order of magnitude greater than those seen in the Fancy white diamonds.

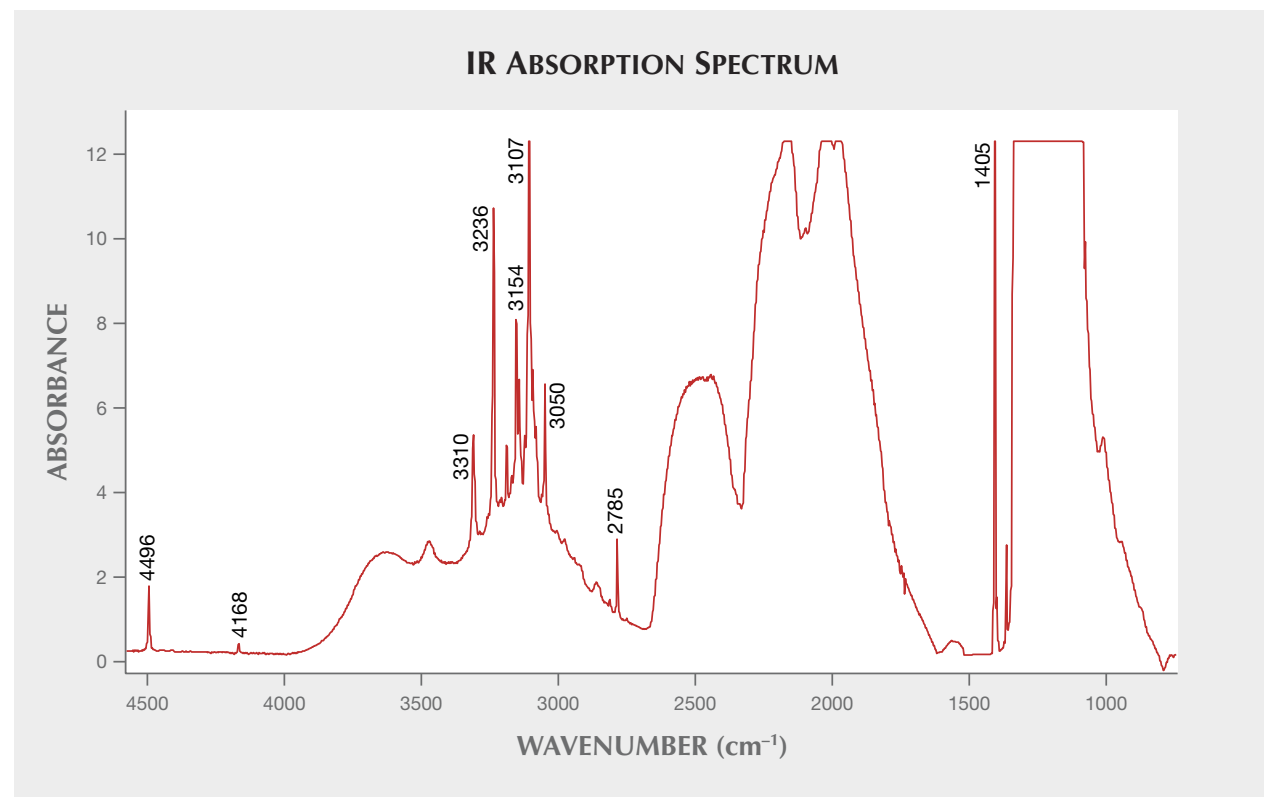

Figure 10. Many Fancy black diamonds have very high intensities of the hydrogen-related peaks-even compared with the "high-hydrogen" Fancy white diamonds (e.g., figures 7 and 8). A typical IR $a b$ sorption spectrum includes saturated nitrogen aggregates and several hydrogen-related peaks, such as a methane-related peak at $3050 \mathrm{~cm}^{-1}$. 

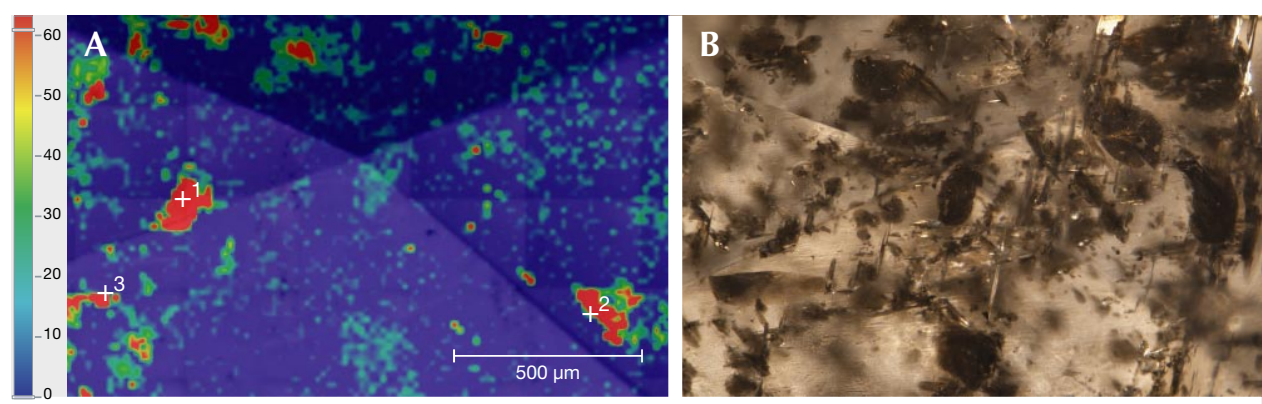

RAMAN SPECTRUM

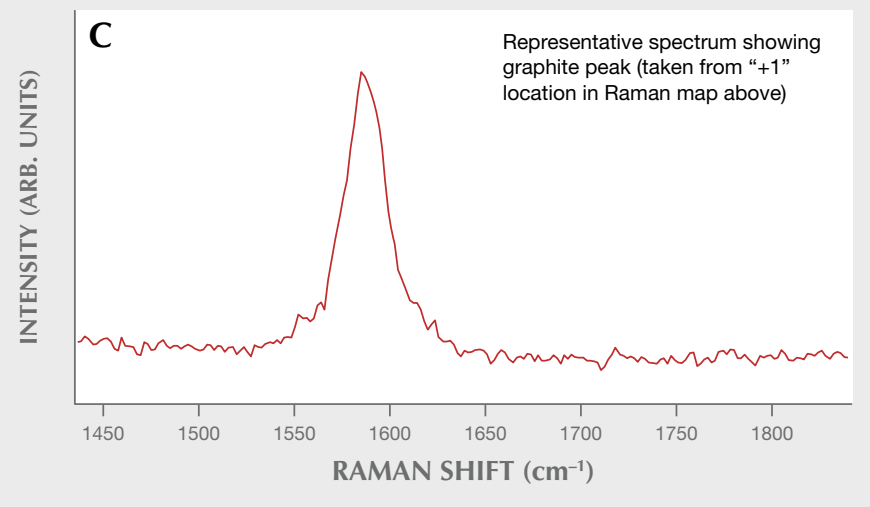

Figure 11. A Raman map (A) was collected on the pavilion side of a 5.27 ct Fancy black diamond (B). The falsecolor map shows the peak area intensity of the graphite peak with a representative peak shown in the Raman spectrum (C). While the Raman map indicates where graphite was detected, a chromite inclusion was detected at " +2 " and a forsterite inclusion was detected at “+3." The pixel size was $15 \mu \mathrm{m}$, and the map is composed from 8,136 spectra collected over five hours.
Although several other publications have identified the crystal inclusions found in Fancy black diamonds (e.g., Titkov et al., 2003; Win and Lu, 2009; Smit et al., 2016, 2018), we provide here for illustrative purposes a Raman map of a typical Fancy black diamond colored by crystal inclusions. Most of the inclusions in this sample proved to be graphite, but a few were identified as other minerals (figure 11). This map, along with the corresponding image, shows that the majority of the crystal inclusions in this particular diamond are graphite.

\section{GEMOLOGICAL OBSERVATIONS}

Fancy White. The microscopic observations reported by GIA gemologists generally mentioned the presence of whitish clouds and a hazy appearance, which is to be expected for diamonds in this color range.

Blue fluorescence is the most common color to be observed with long-wave UV excitation (figure 12, left). Among the 329 type IaB diamonds identified from the 400-stone subset, a majority (254 of the 262 with reported fluorescence reaction) showed blue fluorescence due to the N3 defect, most of them with medium-strength intensity. Only seven showed a weak yellow fluorescence, and one displayed no fluorescence.

Among the other diamond types, IaAB diamonds all showed medium to strong blue fluorescence. Sat- urated type Ia diamonds similarly exhibited medium to strong blue fluorescence, though 8 of the 32 showed a weak yellow and one had no fluorescence. Among the 17 type IIa diamonds, 10 showed a weak blue fluorescence, 2 a weak yellow, and the others no observable reaction.

Some diamonds have a very strong blue fluorescence, and terms such as "hazy" or "milky" are used to describe these (Moses et al., 1997). The 127 ct Portuguese diamond at the Smithsonian Institution is a famous example of an "overblue" - that is, a diamond with a reportedly hazy appearance due to strong blue fluorescence. Nevertheless, the "hazy" appearance due to very strong fluorescence and the "hazy" observation in Fancy white diamonds appear to be unrelated phenomena. Figure 12 (bottom) shows a similar distribution of fluorescence intensities among the transparent type IaB diamonds and the Fancy white type IaB stones. While Fancy white diamonds show a higher incidence of faint and medium fluorescence, only a small percentage in each grouping show strong fluorescence and none showed very strong fluorescence. There is no pronounced shifting to strong or very strong fluorescence among the milky or Fancy white diamonds, which might be expected if the haziness observed in "overblue" diamonds coincided with the nano-inclusions creating the Fancy white color. 


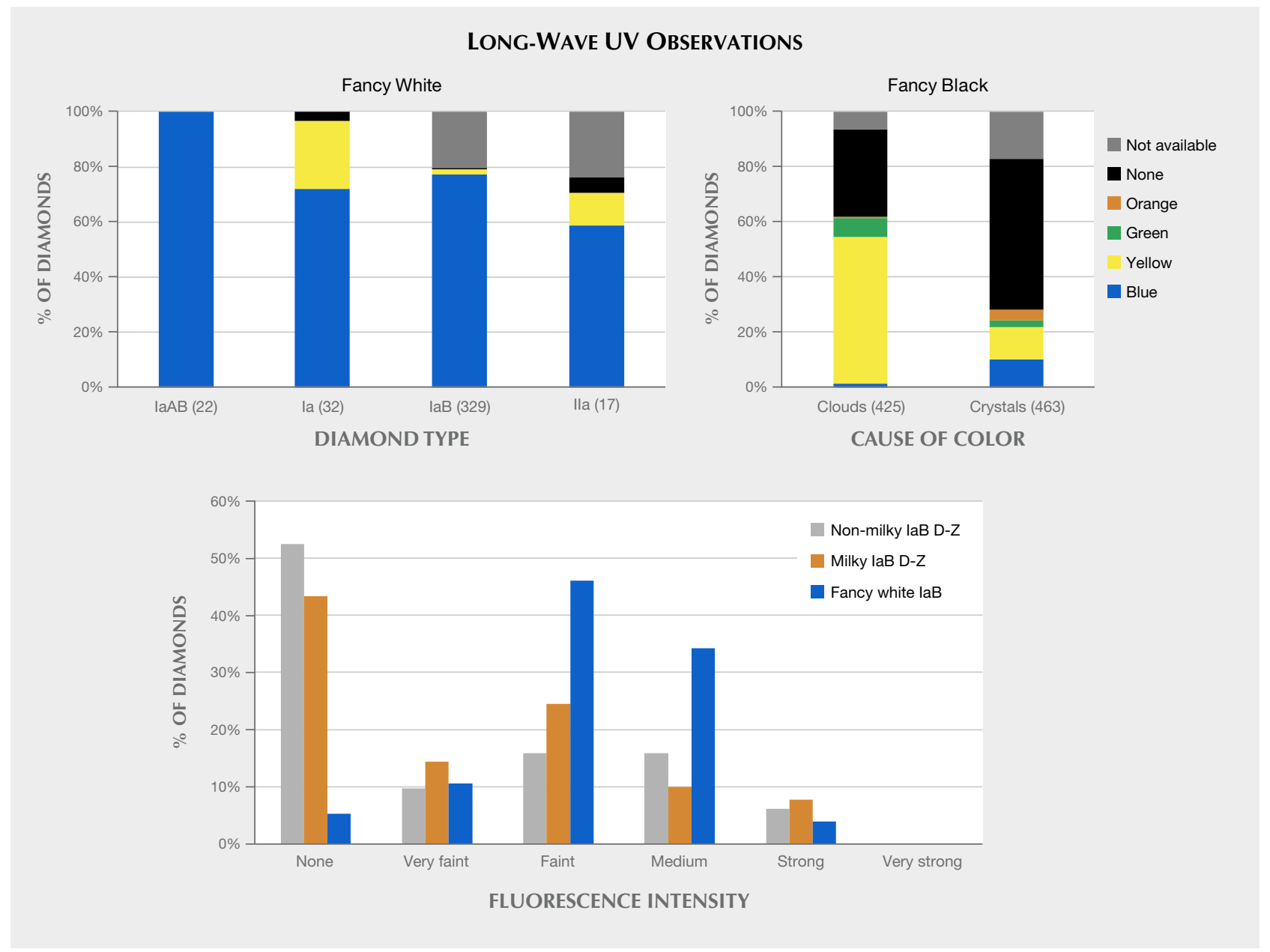

Figure 12. The long-wave UV (365 nm) observations are shown for Fancy white as distinguished by diamond type (left) and Fancy black as distinguished by inclusion type (right). Most Fancy white diamonds showed blue fluorescence due to the N3 defect, while most Fancy black diamonds displayed a weak yellow or no response. Those diamonds identified as having either clouds or crystals as the cause of color are plotted. Those Fancy black diamonds with color due to absorption or polycrystalline diamond are not plotted, and they showed no fluorescence. Bottom: A comparison of the three different groups of type IaB diamonds described earlier and also plotted in figure 8. The fluorescence intensities do not vary much between the different groupings or shift significantly toward strong or very strong fluorescence. These observations were made by laboratory staff following normal grading procedures.

Fancy Black. Microscopic Observations. While examining Fancy black diamonds, GIA gemologists note their observations of the cause of color, such as dark crystal inclusions or clouds, along with other features that generally do not contribute to the diamond color. We catalogued gemologist observations for 1,000 Fancy black diamonds and grouped them based on whether the cause of color was:

- Crystal inclusions-either as graphite, such as those seen in Smit et al. (2018), or as foreign minerals, such as those seen by Titkov et al. (2003).

- Clouds of nano-inclusions (generally assumed as graphite and verified in some cases); see Smit et al. $(2016,2018)$ and Eaton-Magaña et al. (2017).

- A high concentration of absorption defects, polycrystalline diamond, or radiation stains (usually as a contributing factor; Smit et al., 2018).

Figure 13 shows the compilation of these gemological observations for 1,000 Fancy black diamonds. Crystal inclusions were reported in $46 \%$ of the diamonds, some of which also contained radiation stains; $43 \%$ of the observations noted clouds, and a significant percentage of those also contained radiation stains. An additional $10 \%$ of the observations noted the presence of both crystals and clouds. Only 


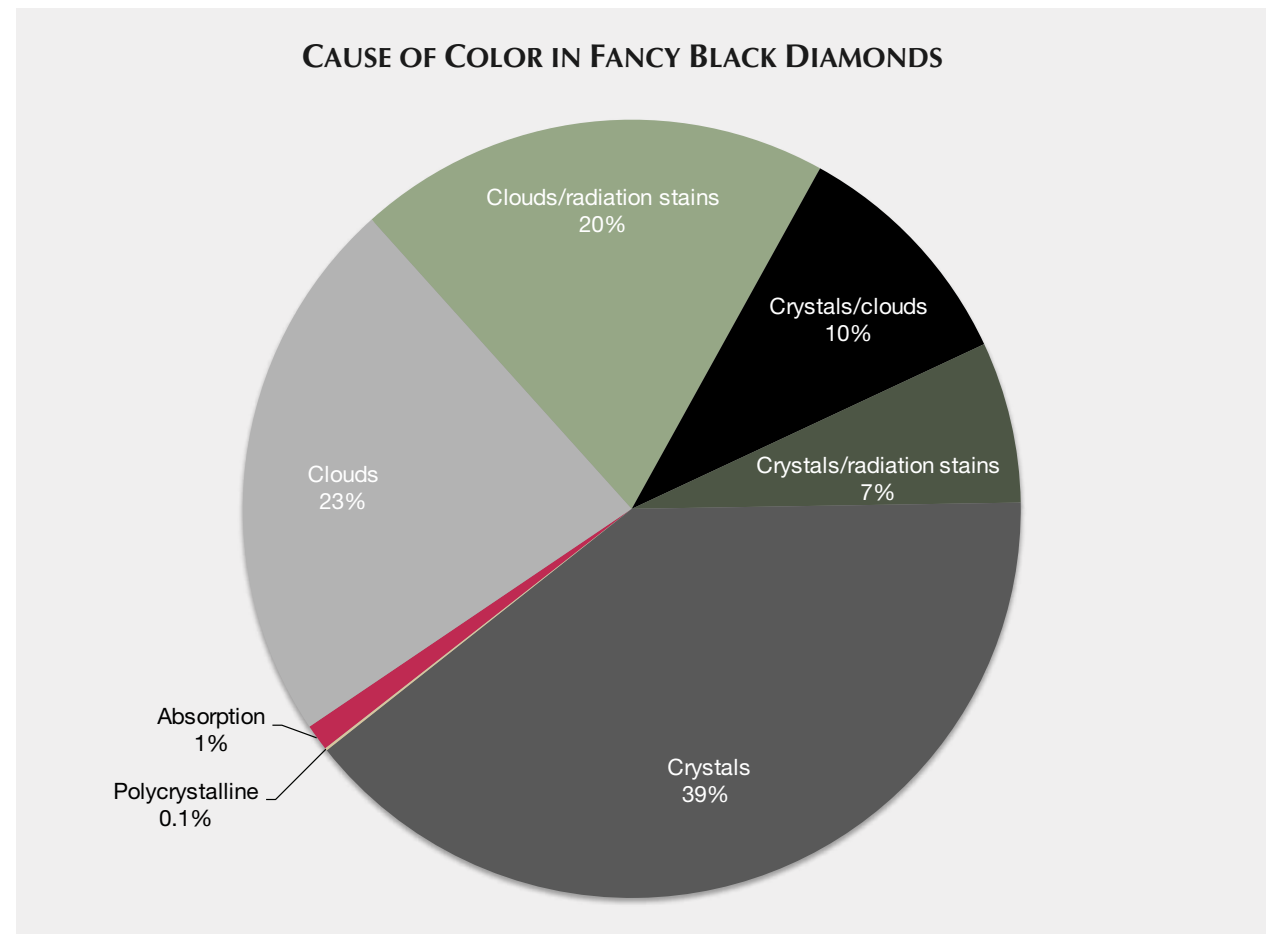

Figure 13. Observations noted by the gemologist for 1,000 randomly selected Fancy black diamonds were chronicled to determine the major causes of color documented in each. A roughly equal distribution was seen for "clouds" (either with or without radiation stains) and for "crystals" (either with or without radiation stains). In another $10 \%$, both features were mentioned. A very small percentage of diamonds were Fancy black due to absorbing defects or polycrystalline diamond growth.

$1 \%$ of the stones had strong absorption; generally these had a deep violet to purple color observed through the pavilion, consistent with previously published Lab Notes entries (e.g., Breeding and Rockwell, 2009) and absorption spectra consistent with violetrelated hydrogen bands (e.g., Eaton-Magaña et al., 2018a).

The radiation stains were generally described as brown rather than green, consistent with Smit et al. (2018) and an indication that these diamonds likely had been heated above $550^{\circ} \mathrm{C}$. In 116 of the 1,000 diamonds, the gemologist noted the presence of iron oxide stains, although such stains are generally not sufficient to affect the color.

Additionally, because so many of these diamonds are heavily included, many such inclusions break the facet surface, which can lead to a textured surface and noticeable polish lines (figure 14). Differential hardness due to inclusions in black diamond is known to create serious challenges in polishing these stones.

Long-Wave UV Fluorescence. Figure 12 (right) shows the color distribution of long-wave UV fluorescence for diamonds characterized by either crystal inclusions or clouds. Almost all that showed fluorescence had weak intensity, regardless of the observed color. Most of those colored by clouds had either weak yellow or no fluorescence, while most colored by crystal inclusions exhibited no fluorescence.

\section{IDENTIFICATION CONCERNS}

Fancy White. For Fancy white diamonds, there is no known method of treatment to mimic the cloudy and hazy appearance formed by the nano-inclusions in natural diamonds in this color range. To date, GIA has not observed a treated or laboratory-grown Fancy white diamond.

However, since the IR peak at $3085 \mathrm{~cm}^{-1}$ that has been associated with milky diamonds (Gu et al., 2018) can be generated by annealing (Kupriyanov et al., 2006), some have speculated that it might be possible to obtain a hazy diamond from a hydrogen- and $\mathrm{B}$ center nitrogen-enriched diamond by HPHT treatment. However, we have never encountered a diamond known to be treated in this way.

Fancy Black. In contrast, there are several methods to create Fancy black color in diamonds by treatment. Over one-third of the black diamonds examined by the laboratory have been treated, so it is important to understand that all Fancy black diamonds have the potential to be treated or synthetic and should be sent to a gemological laboratory for confirmation. Today, the most common method for creating this black color is heating a diamond to high temperatures under vacuum to allow pervasive graphitization of preexisting fractures or inclusions (Overton and Shigley, 2008). This is done on heavily fractured diamonds or on diamonds that contain abundant clouds of micro-inclu- 

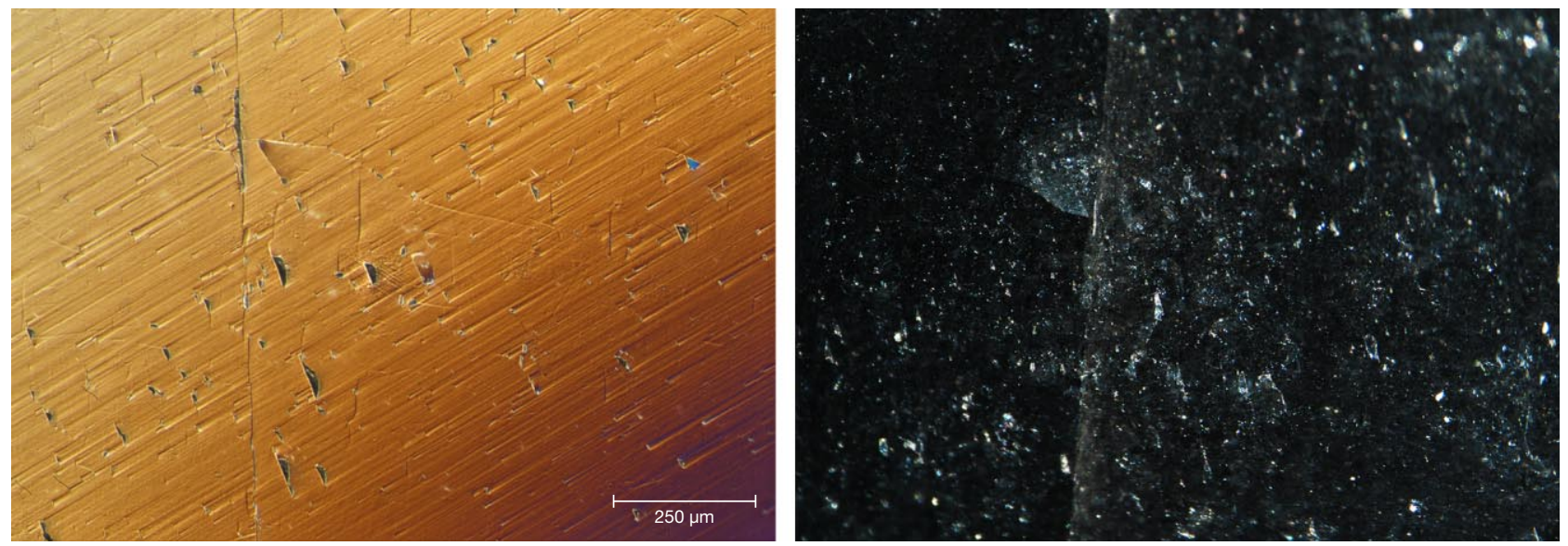

Figure 14. The table facet of a $1.78 \mathrm{ct} \mathrm{Fancy} \mathrm{black} \mathrm{pear} \mathrm{is} \mathrm{shown} \mathrm{under} \mathrm{differential} \mathrm{interference} \mathrm{contrast} \mathrm{lighting}$ (see Renfro, 2015) that enhances the surface topography (left) and in reflected light (right). The differential interference contrast image shows features interrupting the facet surface and visible polish lines. Such an image collected on a typical colorless diamond would appear featureless.

sions and often initially have a grayish appearance (Eaton-Magaña et al., 2017).

Early treatments to produce black color involved introduction of very high concentrations of defects by heavy irradiation treatment. At lower doses, this irradiation would typically give the diamond a fancy blue or green color, but extremely high irradiation doses produce so many light-absorbing defects that the stone has a very dark appearance. Some of these historically treated diamonds have been found to emit measurable radioactivity (Overton and Shigley, 2008). Diamonds that have been heavily irradiated (Hainschwang et al., 2009) often show a dark greenish appearance when examined through the pavilion with fiber-optic light yet appear Fancy black when viewed face-up. They have a dark brown appearance if annealed after the irradiation treatment.

Additionally, some CVD-grown diamonds have been manufactured with such a high concentration of nitrogen-vacancy (NV) centers that they appear Fancy black, while appearing reddish in intense transmitted light. All Fancy black diamonds-whether their color derives from micro-inclusions, graphitization, or a high quantity of defects-should have their color origin confirmed by a gemological laboratory.

\section{CONCLUSIONS}

Although Fancy white and Fancy black diamonds do not occur in large numbers, they create an interesting niche in the fancy-color diamond world. The ingredients creating color in most natural diamonds are atomic-scale defects. Here, Fancy white and Fancy black diamonds (figure 15) typically receive their color from nano-inclusions (generally described as clouds of pinpoints) to micro-sized crystal inclusions.

Figure 15. This snake ring with black and colorless diamonds, from the Malafemmina collection by Dada Arrigoni, contains 3.60 carats of black diamonds. Photo (C) Dada Arrigoni.

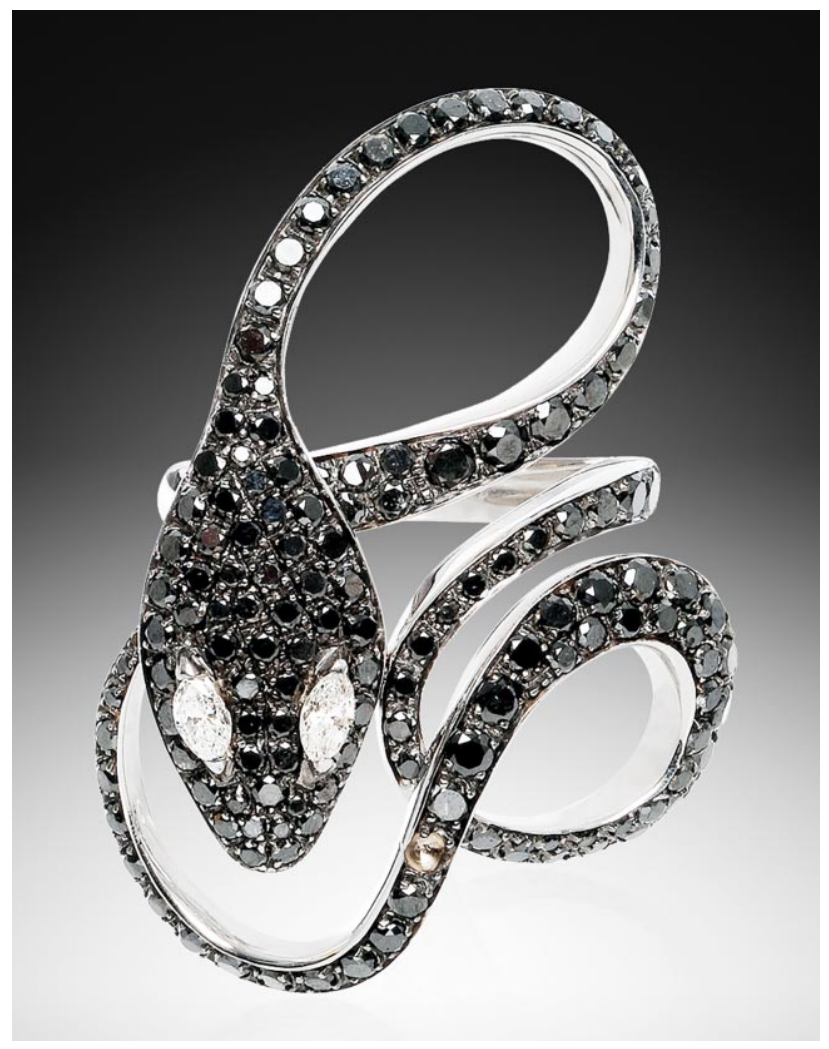


In Fancy white diamonds, the vast majority $(82 \%)$ are type $\mathrm{IaB}$, and recent research (e.g., Gu and Wang, 2017; Gu et al., 2019) has shown these to have a sublithospheric origin in either the transition zone or the lower mantle, which has helped diagnose the cause of color in these enigmatic gems. When diamond is formed under superdeep conditions, they are exposed to higher pressures and temperatures than the vast majority of diamonds that form within the lithosphere. The effect of higher temperatures likely contributes to the complete aggregation of the nitrogen (from single nitrogen to $\mathrm{A}$ aggregates to $\mathrm{B}$ aggregates) and other high-temperature effects such as destruction of the platelets that potentially aid in forming the dislocation loops or the nitrogen-bearing nano-inclusions that lead to the "milky" appearance of Fancy white diamonds. Additionally, nickel- and hydrogen-related defects were seen in much greater numbers in Fancy white type IaB diamonds than in their transparent coun- terparts. The normalized intensity of the $3107 \mathrm{~cm}^{-1}$ peak in FTIR was about one order of magnitude higher in Fancy white diamonds than in high-clarity D-to-Z type IaB diamonds.

The last few years have proven interesting for both of these classes of colored diamonds. The Marange deposit has become a reliable source for natural Fancy black diamonds in which the black color is caused principally through graphitic inclusions or clouds and the presence of radiation stains contributing to the dark color. This comparatively recent source has inclusions that are distinctly different from other documented mines such as the Mir kimberlite pipe, in which non-graphitic mineral inclusions are the major cause of color.

The ability to examine such a large number of colored diamonds and perform systematic data collection provides a unique opportunity to document gemological and spectroscopic trends in these diamonds that would likely not be possible otherwise.
ABOUT THE AUTHORS

Dr. Eaton-Magaña and Dr. Breeding are senior research

scientists, Mr. Ardon is a research associate, and Dr. Shigley is a

distinguished research fellow, at GIA in Carlsbad, California.

\section{ACKNOWLEDGMENTS}

The authors thank Dr. Tingting Gu, Dr. Chloe Peaker, and the peer reviewers for their suggestions on this article. We also thank GIA's Garrett McElhenny and Alex Balter for their assistance with data compilation.

\section{REFERENCES}

Balfour I. (2009) Famous Diamonds. Antique Collector's Club, Woodbridge, England.

Boyd S.R., Kiflawi I., Woods G.S. (1995) Infrared absorption by the B nitrogen aggregate in diamond. Philosophical Magazine B, Vol. 72, No. 3, pp. 351-361, http://dx.doi.org/10.1080/ 13642819508239089

Breeding C.M., Shigley J.E. (2009) The "type" classification system of diamonds and its importance in gemology. Ge G, Vol. 45, No. 2, pp. 96-111, http://dx.doi.org/10.5741/GEMS.45.2.96

Breeding C.M., Rockwell K.M. (2009) Lab Notes: "Black" diamond with deep violet color. $G \uplus G$, Vol. 45, No. 2, p. 135.

Breeding C.M., Eaton-Magaña S.C., Shigley J.E. (2018) Naturalcolor green diamonds: A beautiful conundrum. $G \uplus G$, Vol. 54, No. 1, pp. 2-27, http://dx.doi.org/10.5741/GEMS.54.1.2

Collins A.T., Kanda H., Isoya J., Ammerlaan C.A.J., van Wyk J.A. (1998) Correlation between optical absorption and EPR in highpressure diamond grown from a nickel solvent catalyst. Diamond and Related Materials, Vol. 7, No. 2/5, pp. 333-338, http://dx.doi.org/10.1016/S0925-9635(97)00270-7

De Corte K., Kerremans Y., Nouven B., Van Royen J. (2004) Characterization of carbonado as a gem. Gemmologie - Zeitschrift der Deutschen Gemmologischen Gesellschaft, Vol. 53, No. 1, pp. 5-22.

Eaton-Magaña S., Ardon T., Zaitsev A.M. (2017) Inclusion and point defect characteristics of Marange graphite-bearing diamonds after high temperature annealing. Diamond and Related Materials, Vol. 71, pp. 20-29, http://dx.doi.org/10.1016/ j.diamond.2016.11.011

Eaton-Magaña S.C., Breeding C.M., Shigley J.E. (2018a) Naturalcolor blue, gray, and violet diamonds: Allure of the deep. $G \uplus G$, Vol. 54, No. 2, pp. 112-131, http://dx.doi.org/10.5741/GEMS. 54.2.112

Eaton-Magaña S.C., Ardon, T., Smit K.V. Breeding C.M., Shigley J.E. (2018b) Natural-color pink, purple, red, and brown diamonds: Band of many colors. GÆG, Vol. 54, No. 4, pp. 352377, http://dx.doi.org/10.5741/GEMS.54.2.352

Evans T., Kiflawi I., Luyten W., Van Tendeloo G., Woods G.S. (1995) Conversion of platelets into dislocation loops and voidite formation in type IaB diamonds. Proceedings of the Royal Society of London. Series A: Mathematical and Physical Sciences, Vol. 449, No. 1936, pp. 295-313, http://dx.doi.org/ 10.1098/rspa.1995.0045

Fritsch E., Hainschwang T., Massi L., Rondeau B. (2007) Hydrogen-related optical centers in natural diamond: An update. New Diamond and Frontier Carbon Technology, Vol. 17, No. 2, pp. 63-89.

Goss J.P., Briddon P.R., Hill V., Jones R., Rayson M.J. (2014) Identification of the structure of the $3107 \mathrm{~cm}^{-1} \mathrm{H}$-related defect in 
diamond. Journal of Physics: Condensed Matter, Vol. 26, No. 14, pp. 1-6, http://dx.doi.org/10.1088/0953-8984/26/14/145801

Gu T., Wang W. (2017) IaB diamond and its geological implications. International Kimberlite Conference: Extended Abstracts. Vol. 11

Gu T., Wang W. (2018) Optical defects in milky type IaB diamonds. Diamond and Related Materials, Vol. 89, pp. 322-329, http://dx.doi.org/10.1016/j.diamond.2018.09.010

Gu T., Ohfuji H., Wang W. (2019) Origin of milky optical features in type IaB diamonds: dislocations, nano-inclusions, and polycrystalline diamond. American Mineralogist, Vol. 104, No. 5, pp. 652-658, http://dx.doi.org/10.2138/am-2019-6699

Haggerty S.E. (2017) Carbonado diamond: A review of properties and origin. $G \uplus G$, Vol. 53 No. 2, pp. 168-179, http://dx.doi.org/ 10.5741/GEMS.53.2.168

Hainschwang T., Simic D., Fritsch E., Deljanin B., Woodring S. Del Re N. (2005) A gemological study of a collection of chameleon diamonds. GeG, Vol. 41, No. 1, pp. 20-35, http://dx.doi.org/10.5741/GEMS.41.1.20

Hainschwang T., Respinger A., Notari F., Hartmann H.J., Gunthard C. (2009) A comparison of diamonds irradiated by high fluence of neutrons or electrons, before and after annealing. Diamond and Related Materials, Vol. 18, No. 10, pp. 1223-1234, http://dx.doi.org/10.1016/j.diamond.2009.04.011

Humble P. (1982) The structure and mechanism of formation of platelets in natural type Ia diamond. Proceedings of the Royal Society of London A, Vol. 381, No. 1780, pp. 65-81, http://dx.doi.org/10.1098/rspa.1982.0059

Jang-Green H. (2006) Lab Notes: Unusually large Fancy white diamond with whitish banding. $G \uplus G$, Vol. 42, No. 4, pp. $262-$ 263.

Johnson P. (2008) Lab Notes: Black diamonds colored by hydrogen clouds. $G \uplus G$, Vol. 44, No. 3, p. 254

Johnson P. (2011) Lab Notes: A strongly purple-colored black diamond. Ge G, Vol. 47, No. 4, p. 309.

Kagi H., Zedgenizov D.A., Ohfuji H., Ishibashi H. (2016) Microand nano-inclusions in a superdeep diamond from São Luiz, Brazil. Geochemistry International, Vol. 54, No. 10, pp. 834838, http://dx.doi.org/10.1134/S0016702916100062

Kammerling R.C., Kane R.E., Koivula J.I., McClure S.F. (1990) An investigation of a suite of black diamond jewelry. $G \uplus G$, Vol. 26, No. 4, pp. 282-287, http://dx.doi.org/10.5741/GEMS.26.4.282

Klein-BenDavid O., Wirth R., Navon O. (2007) Micrometer-scale cavities in fibrous and cloudy diamonds - A glance into diamond dissolution events. Earth and Planetary Science Letters, Vol. 264, No. 1/2, pp. 89-103, http://dx.doi.org/10.1016/ j.epsl.2007.09.004

Koivula J.I., Kammerling R.C., Fritsch E. (1992) Gem News: Tucson' 92 report. $G \uplus G$, Vol. 28 , No. 1, p. 58 .

Kupriyanov I.N., Pal'yanov Y.N., Shatsky V.S., Kalinin A.A., Nadolinnyi V.A., Yur'eva O.P. (2006) Study of the transformation of hydrogen-containing centers in diamond at high PT parameters. Doklady Earth Science, Vol. 406, No. 1, pp. 69-73.

Lang A.R. (1974) On the growth-sectorial dependence of defects in natural diamonds. Proceedings of Royal Society A, Vol. 340, No. 1621, pp. 233-248, http://dx.doi.org/10.1098/rspa.1974.0150

Moses T.M., Reinitz I.M., Johnson M.L., King J.M., Shigley J.E. (1997) A contribution to understanding the effect of blue fluorescence on the appearance of diamonds. $G \uplus G$, Vol. 33, No. 4, pp. 244-259, http://dx.doi.org/10.5741/GEMS.33.4.244

Nasdala L., Grambole D., Wildner M., Gigler A.M., Hainschwang T., Zaitsev A.M., Harris J.W., Milledge J., Schulze D., Hofmeister W., Balmer W.A. (2013) Radio-colouration of diamond: A spectroscopic study. Contributions to Mineralogy and Petrology, Vol. 165, No. 5, pp. 843-861, http://dx.doi.org/10.1007/ s00410-012-0838-1
Navon O., Wirth R., Schmidt C., Jablon B.M., Schreiber A., Emmanuel S. (2017) Solid molecular nitrogen $\left(\delta-N_{2}\right)$ inclusions in Juina diamonds: Exsolution at the base of the transition zone. Earth and Planetary Science Letters, pp. 1-11. Vol. 464, pp. $237-247$.

Overton T.W., Shigley J.E. (2008) A history of diamond treatments. GÆG, Vol. 44, No. 1, pp. 32-55, http://dx.doi.org/10.5741/ GEMS.44.1.32

Renfro N. (2015) Digital photomicrography for gemologists. $G \uplus G$, Vol. 51, No. 2, pp. 144-159, http://dx.doi.org/10.5741/ GEMS.51.2.144

Rudloff-Grund J., Brenker F.E., Marquardt K., Howell D., Schreiber A., O'Reilly S.Y., Griffin W.L., Kaminsky F.V. (2016) Nitrogen nanoinclusions in milky diamonds from Juina area, Mato Grosso State, Brazil. Lithos, Vol. 265, pp. 57-67, http://dx.doi.org/ 10.1016/j.lithos.2016.09.022

Shirey S.B., Shigley J.E. (2013) Recent advances in understanding the geology of diamonds. GÆG, Vol. 49, No. 4, pp. 188-222, http://dx.doi.org/10.5741/GEMS.49.4.188

Smit K.V., Shirey S.B., Stern R.A., Steele A., Wang W. (2016) Diamond growth from $\mathrm{C}-\mathrm{H}-\mathrm{N}-\mathrm{O}$ fluids in the lithosphere: evidence from $\mathrm{CH}_{4}$ micro-inclusions and $\delta^{13} \mathrm{C}-\delta^{15} \mathrm{~N}-\mathrm{N}$ content in Marange mixed-habit diamonds. Lithos, Vol. 265, pp. 68-81, http://dx.doi.org/10.1016/j.lithos.2016.03.015

Smit K.V., Myagkaya E., Persaud S., Wang W. (2018) Black diamonds from Marange (Zimbabwe): A result of natural irradiation and graphite inclusions. GÆ G, Vol. 54, No. 2, pp. 132-148, http://dx.doi.org/10.5741/GEMS.54.2.132

Smith E.M., Shirey S.B., Nestola F., Bullock E.S., Wang J., Richardson S.H., Wang W. (2016) Large gem diamonds from metallic liquid in Earth's deep mantle. Science, Vol. 354, No. 6318, pp. 1403-1405, http://dx.doi.org/10.1126/science.aal1303

Smith E.M., Shirey S.B., Richardson S.H., Nestola F., Bullock E.S., Wang J., Wang W. (2018) Blue boron-bearing diamonds from Earth's lower mantle. Nature, Vol. 560, No. 7716, pp. 84-87, http://dx.doi.org/10.1038/s41586-018-0334-5

Speich L., Kohn S.C., Wirth R., Smith C.B. (2017) The relationship between platelet size and the $\mathrm{B}^{\prime}$ infrared peak of natural diamonds revisited. Lithos, Vols. 278-281, pp. 419-426, http://dx.doi.org/10.1016/j.lithos.2017.02.010

Stukowski A., Bulatov V.V., Arsenlis A. (2012). Automated identification and indexing of dislocations in crystal interfaces. Modelling and Simulation in Materials Science and Engineering, Vol. 20, No. 8, p. 085007, http://dx.doi.org/10.1088/09650393/20/8/085007

Tang C.J., Neves A.J., Carmo M.C. (2005) On the two-phonon absorption of CVD diamond films. Diamond and Related Materials, Vol. 14, No. 11/12, pp. 1943-1949, http://dx.doi.org/10.1016/ j.diamond.2005.08.060

Titkov S.V., Zudin N.G., Gorshkov A.I., Sivtsov A.V., Magazina L.O. (2003) An investigation into the cause of color in natural black diamonds from Siberia. $G \uplus G$, Vol. 39, No. 3, pp. 200209, http://dx.doi.org/10.5741/GEMS.39.3.200

Titkov S.V., Shigley J.E., Breeding C.M., Mineeva R.M., Zudin N.G., Sergeev A.M. (2008) Natural-color purple diamonds from Siberia. Ge G, Vol. 44, No. 1, pp. 56-64, http://dx.doi.org/ 10.5741/GEMS.44.1.56

Wang W., Lu R., Moses T. (2009) Photoluminescence features of carbonado diamonds. GIA Research News, July 21, www.gia.edu/ doc/Photoluminescence-Features-of-Carbonado-Diamonds.pdf

Win W.L., Lu R. (2009) Lab Notes: Assemblages of K-feldspar, hematite-magnetite, and quartz in etch channels. $G \uplus G$, Vol. 45 , No. 1 , pp. 54-55.

Woods G.S. (1986) Platelets and the infrared absorption of type Ia diamonds. Proceedings of the Royal Society A, Vol. 407, No. 1832, pp. 219-238, http://dx.doi.org/10.1098/rspa.1986.0094 